\title{
Experimental assessment of the behaviour of bolted T-stub connections made up of welded plates
}

\author{
Ana M. Girão Coelho ${ }^{a}$, Frans S.K. Bijlaard ${ }^{\text {b,* }}$, Nol Gresnigt ${ }^{\text {, }}$, \\ Luís Simões da Silva ${ }^{\mathrm{c}}$ \\ a Department of Civil Engineering, Polytechnic Institute of Coimbra, Quinta da Nora, \\ 3040-228 Coimbra, Portugal \\ b Steel and Timber Structures, Faculty of Civil Engineering and Geosciences, \\ Delft University of Technology, P.O. Box 5048, 2600 GA Delft, \\ The Netherlands \\ c Department of Civil Engineering, University of Coimbra, Polo II, Pinhal de Marrocos, \\ 3030-290 Coimbra, Portugal
}

Received 24 January 2003; accepted 12 August 2003

\begin{abstract}
The results of 32 tests on bolted T-stub connections made up of welded plates are presented and discussed. Although T-stubs have been used for many years to model the tension zone of bolted joints, the research was mainly concentrated on rolled profiles as T-stub elements. To extend this model to the case of welded plates as T-stub elements, a test programme was undertaken at the Delft University of Technology and is reported in this paper. It provides insight into the behaviour of this different type of assembly, in terms of resistance, stiffness, deformation capacity and failure modes, in particular. The key variables tested include the weld throat thickness, the size of the T-stub, the type and diameter of the bolts, the steel grade, the presence of transverse stiffeners and the T-stub orientation. The results show that the welding procedure is particularly important to ensure a ductile behaviour of the connection. Most of the T-stubs failed by tension fracture of the bolts after significant yielding of the flanges. However, some of the specimens have shown early damage of the plate material near the weld toe due to the effect of the welding consumable that induced premature cracking and reduced the overall deformation capacity. A solution to this problem is given by setting requirements to the weld metal to be used.
\end{abstract}

(C) 2003 Elsevier Ltd. All rights reserved.

\footnotetext{
* Corresponding author. Tel.: +31-15-2784581; fax: +31-15-2783173

E-mail address: f.s.k.bijlaard@citg.tudelft.nl (F.S.K. Bijlaard).
} 


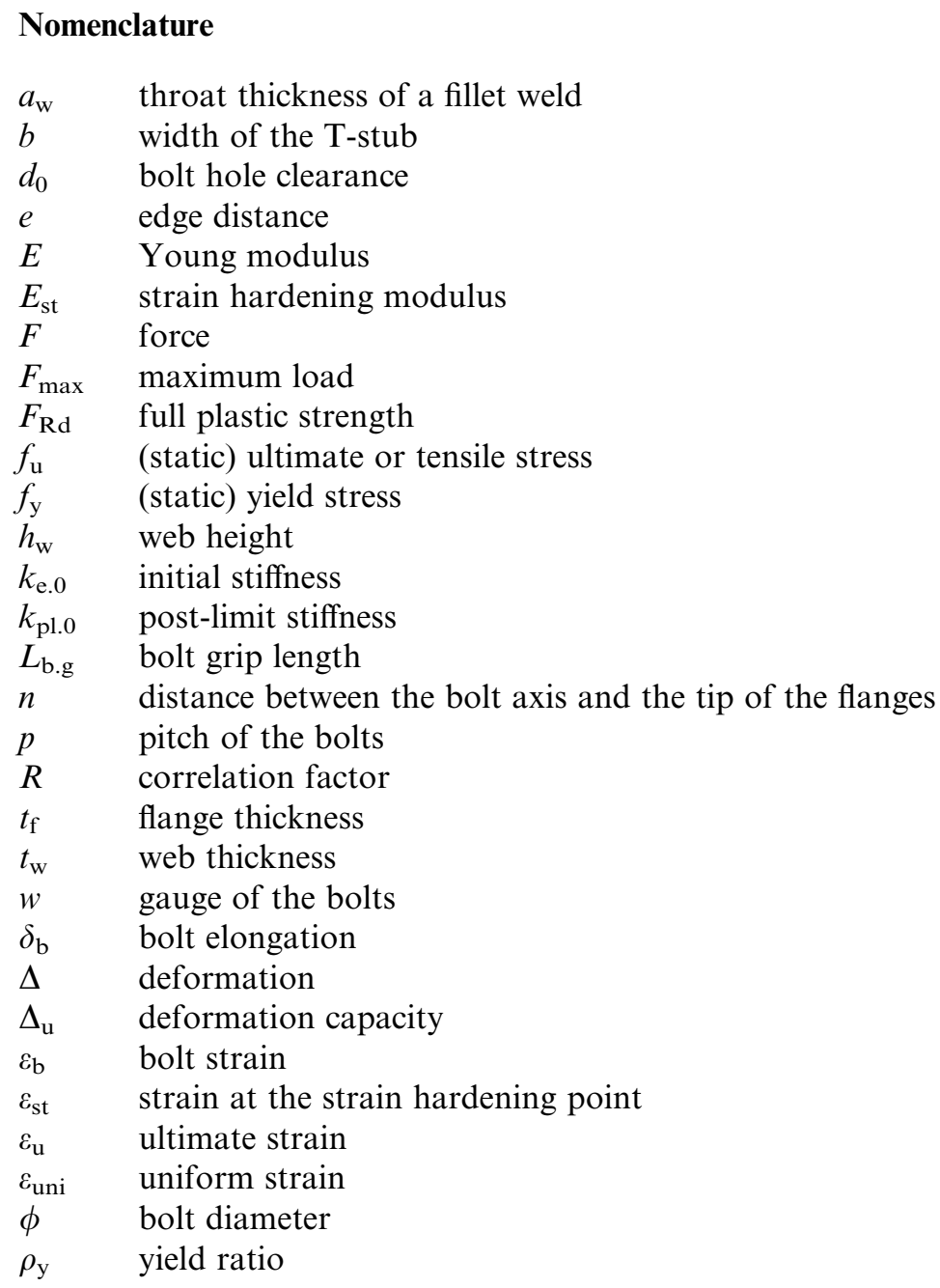

Keywords: Component method; Deformation capacity; Experimental testing; High-strength steel grade; Resistance; Steel connections; Stiffness; T-stub; Welded profiles

\section{Introduction}

The T-stub corresponds to two T-shaped elements connected through the flanges by means of one or more bolt rows. The T-stub model has been extensively applied to model the tension zone of bolted joints that constitutes the most relevant source of deformability of this type of joints. Within the framework of the so-called 
component method [1], this zone includes the following basic elemental parts: column flange, end plate or angles in bending, along with the bolts in tension [2-5]. Fig. 1a identifies the T-stub which accounts for the deformation of the column flange and the end plate in bending in the particular case of an extended end plate bolted connection. In this specific case, because the column flange is unstiffened, the T-stub on the column side is orientated at right angles to the end plate T-stub [4].

The models for the column and the end plate sides are different. The T-stub elements on the column flange side are generally hot rolled profiles, whilst on the end plate side such elements comprise two welded plates, the end plate and the beam flange, and a further additional stiffener that corresponds to the beam web (Fig. 1b). The first model has been extensively studied over the past years and it was the aim of several research programmes that are reported in the literature [2,4-10]. Rules for the prediction of the connection response have been included in modern design codes as the Eurocode 3 [11]. This code approximates the force-deformation $(F-\Delta)$ behaviour of this component by means of an elastoplastic response, characterized by a full plastic strength, $F_{\mathrm{Rd}}$ and initial stiffness, $k_{\mathrm{e} .0}$. The post-limit stiffness, $k_{\mathrm{pl} .0}$ is taken as zero, which means that strain hardening and geometric nonlinear effects

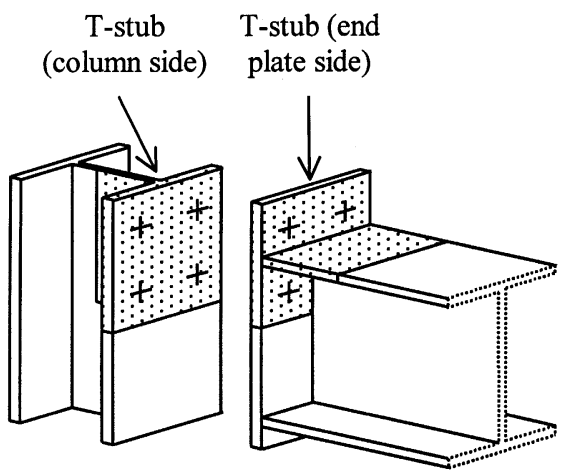

(a) T-stub identification for an unstiffened bolted extended end plate connection.

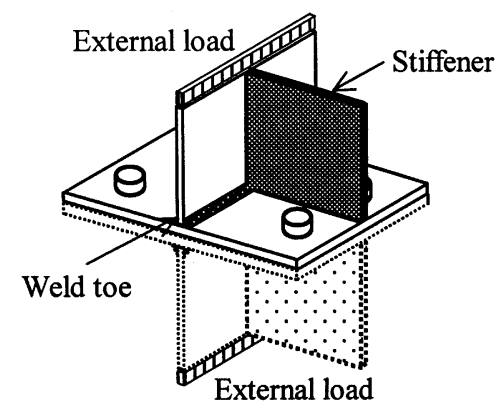

(b) T-stub model for the end plate side.

Fig. 1. Different types of bolted T-stub connection assemblies. 
are neglected. Regarding the component ductility, Eurocode 3 [11] presents some qualitative principles based on the main contributions of the T-stub deformation: if the bending deformation of the flanges governs the plastic mechanism, then the ductility is infinite; should the bolt determine collapse, the ductility is limited. These rules are, however, insufficient to ensure adequate ductility in partial strength joints [12]. To fill in this code gap, several authors have recently proposed analytical or numerical procedures for assessment of the deformation capacity of a T-stub made up of beam rolled profiles [13-15].

The current approach to account for the behaviour of T-stubs made up of welded plates consists in a mere extrapolation of the existing rules for the other assembly type. The authors have shown that this assumption is erroneous and can lead to unsafe estimations of the characteristic properties [16,17]. And since the assemblage end plate-fasteners (welds and bolts) is often the weakest joint part, the characterization of its behaviour is very important. This paper focuses on the experimental research of the monotonic deformation response of welded plate T-stub connections. The experiments were carried out at the Delft University of Technology. Their primary intent was to provide insight of the actual behaviour of this type of connection, failure modes and deformation capacity. Also, the role of the welding and the presence of transverse stiffeners must be fully understood. Finally, this programme adds further examples to a database for future calibration of analytical and/or numerical models.

\section{Description of the experimental programme}

\subsection{Geometrical properties of the specimens}

The basic configuration of the test specimens comprised two plates of $10.0 \mathrm{~mm}$ thickness. The plates were welded together by means of a continuous $45^{\circ}$-fillet weld with similar plate characteristics. Snug-tightened high-strength bolts fastened the T-stub elements. The unstiffened specimens were designed to fail according to a plastic collapse mode 1 [11]. This plastic collapse mechanism is characterized by the formation of four plastic hinges (double curvature of the flanges): two hinges at the bolt axes and two hinges at the flange-to-web connection. According to Eurocode 3 [11], this plastic collapse type ensures a good ductility of the connection.

The general characteristics of the specimens are illustrated in Fig. 2 and the details are given in Table 1. Both nominal and actual properties are reported. The actual geometry was measured before testing of the specimens and is listed in Table 1 as an average value of the several T-stub elements from each series. In series WT7 and WT57, the T-stub elements were fastened by means of one bolt row only due to equipment limitation. The two T-stub elements for most series are symmetrical. For series WT64A and WT64B, the T-stub elements included a stiffener only on one side of the connection. 


\section{$\underline{\text { Section xx }}$}

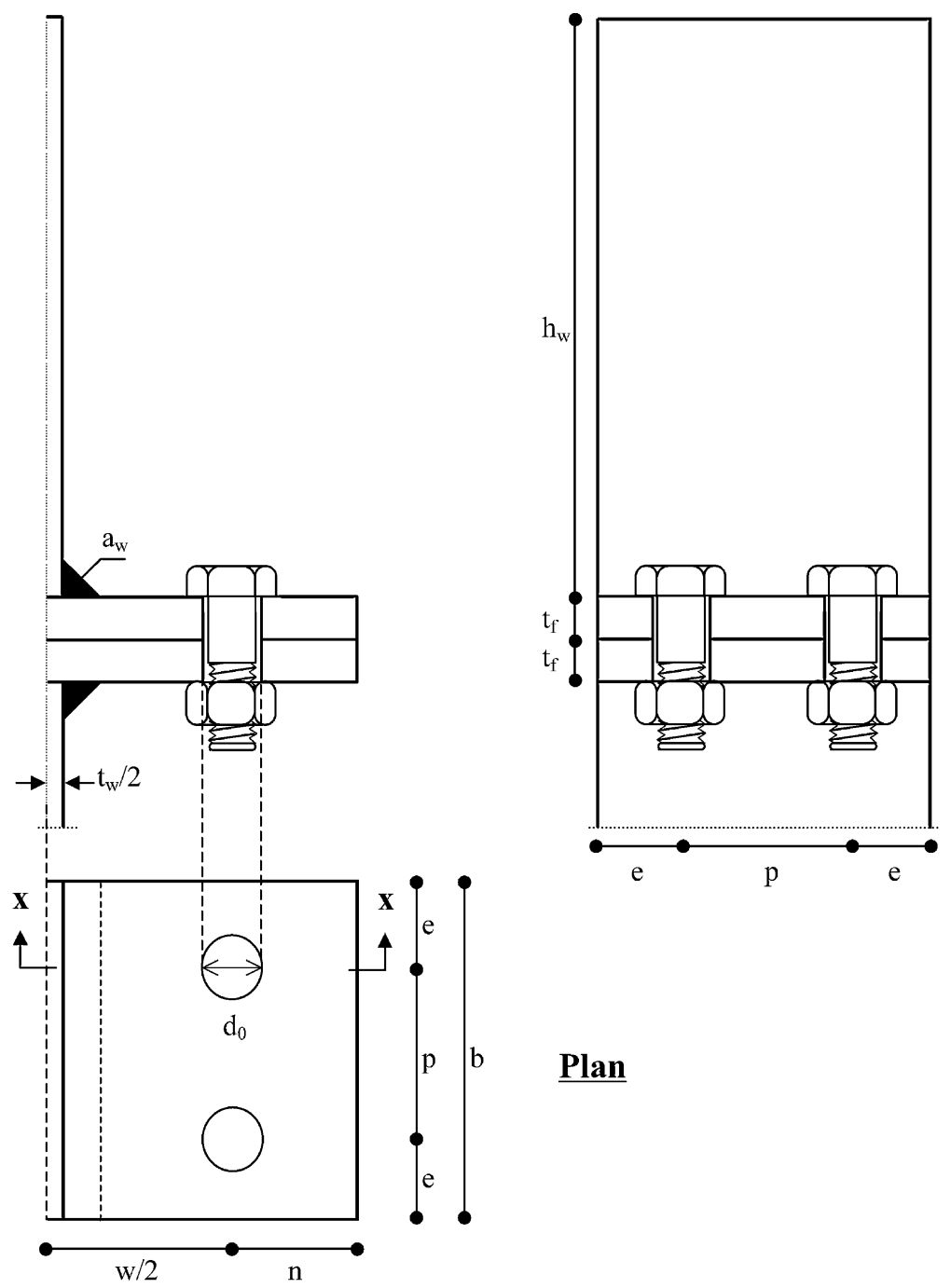

Fig. 2. T-stub specimen general characteristics.

\subsection{Mechanical properties of the specimens}

\subsubsection{Tension tests on the bolts}

In order to characterize the mechanical properties of the M12, grade 8.8 and 10.9 bolts, two series of experiments were performed. In the first series, the actual bolt (short-threaded, ST or full-threaded, FT) was tested under tension (Fig. 3a). Failure always occurred in the threaded region. This type of test does not provide 


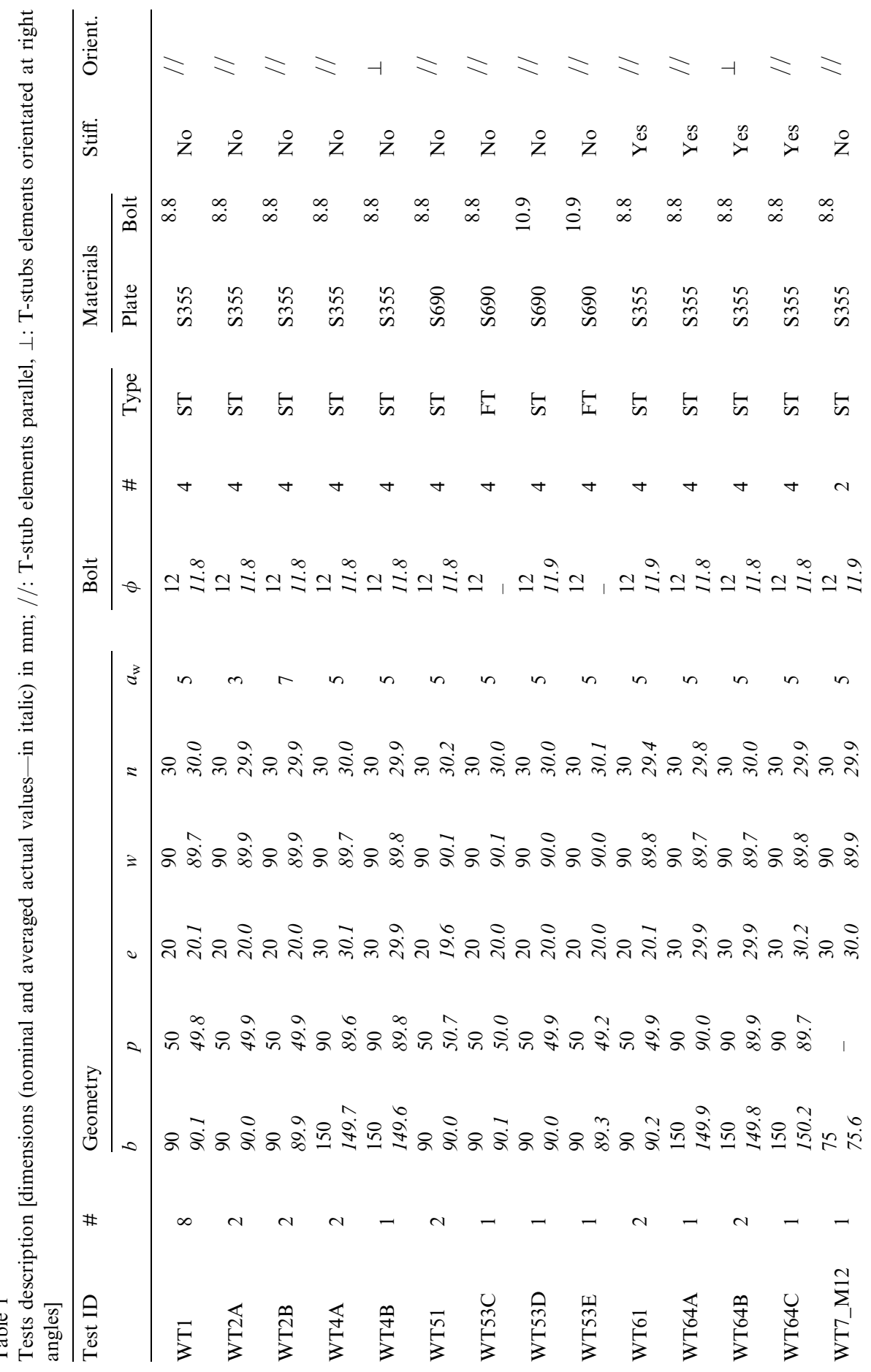




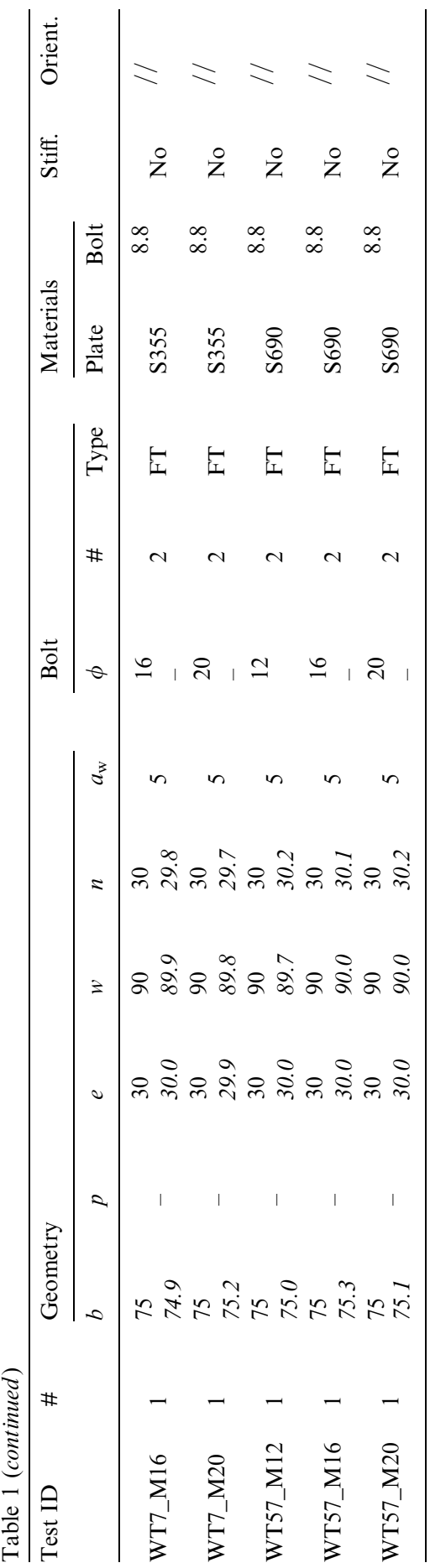




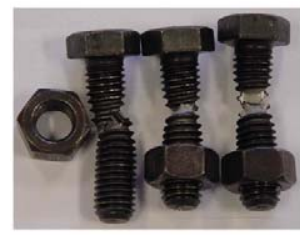

Group 1 (grade 8.8)

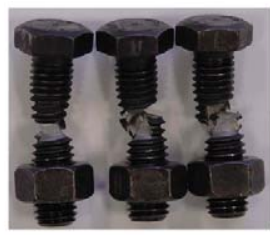

Group 3 (grade 10.9)

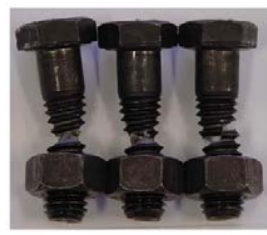

Group 2 (grade 8.8)

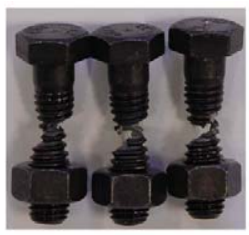

Group 4 (grade 10.9)

(i) Full-threaded specimens.

(ii) Short-threaded specimens.

(a) First series: "actual" bolts.

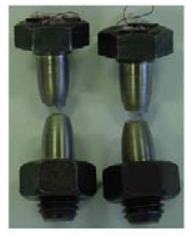

Group 1 (grade 8.8) Group 3 (grade 10.9)

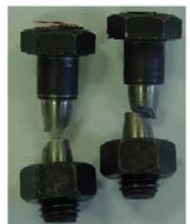

Group 2 (grade 8.8)

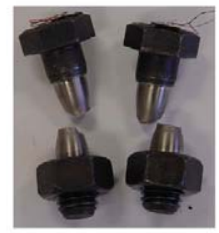

Group 4 (grade 10.9)

(i) Full-threaded specimens.

(ii) Short-threaded specimens.

(b) Second series: machined bolts.

Fig. 3. Bolt specimens: two series of tests.

enough data to determine the Young modulus, $E$ and the proof strength of the bolt. Then, in a second test series, the bolts were machined so that the threads within the bolt grip were removed and a constant diameter was obtained (Fig. 3b). This procedure is not expected to introduce major influences on the bolt behaviour since the removal of the material was limited to the threads, even though the bolt mechanical properties are not uniform.

Both specimen types were tested in tension under displacement control in a special device as shown in Fig. 4. The elongation behaviour of the bolt was measured by means of a measuring bracket (or horseshoe device, also depicted in Fig. 4) in the first series of tests and by means of internal strain gauges in the second. The strain gauges (TML-BTM-6C) can measure strains up to $6000 \mu \mathrm{m} / \mathrm{m}$. The graphs from Fig. 5a plot the bolt elongation curve for one of the short-threaded M12 grade 8.8 (group 2) tested bolts. The graph includes the load cell displacement results and the measuring bracket data up to its removal in the elastic range. Clearly, the results obtained from the measuring bracket are stiffer since the displacement of the actuator also includes the slippery of the clamps. Fig. 5b traces the force-strain results obtained for an identical bolt type (now chosen from the second test series). Naturally, the maximum load level in the latter case decreases, as the bolt tensile area is smaller. To verify the accuracy of the special bolt measuring 


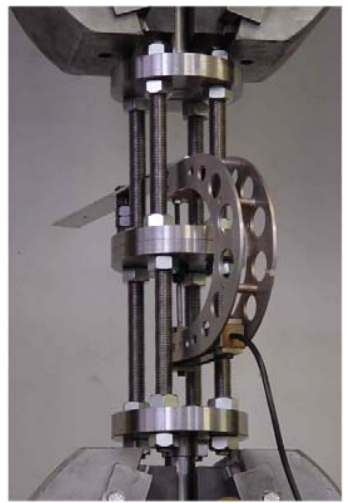

Fig. 4. Test rig for the bolt tensile testing and horseshoe device.

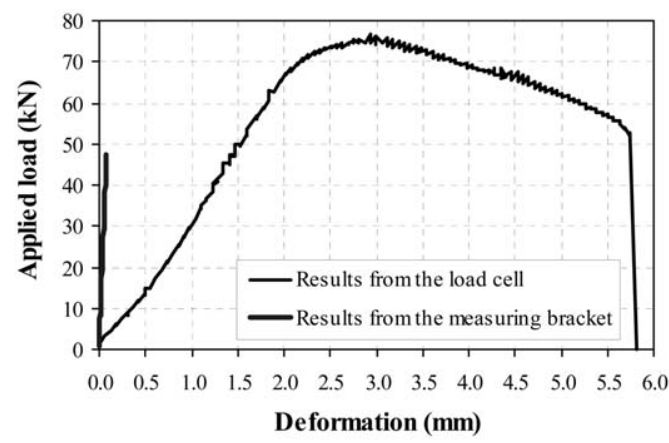

(a) Bolt elongation behaviour.

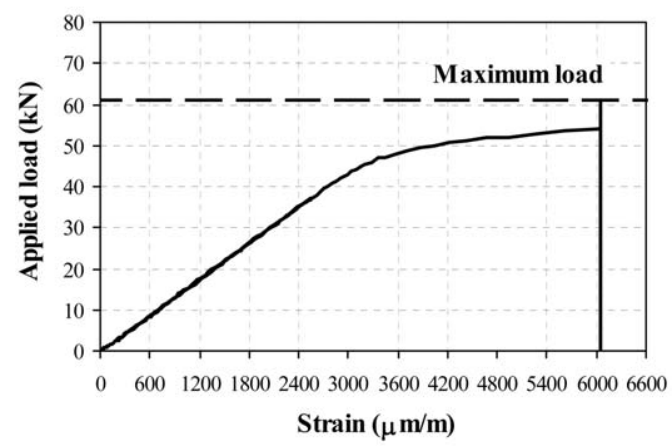

(b) Bolt strain behaviour.

Fig. 5. Bolt tensile response (e.g. bolt from group 2). 


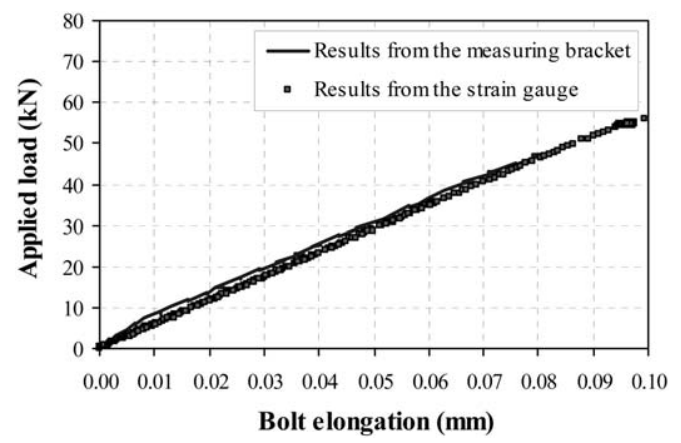

Fig. 6. Comparison of the bolt experimental (elastic) results for both test series (bolt from group 2).

bracket, Fig. 6 compares the elastic deformation of two bolts from the same group 2 , representing each bolt series. The bolt elongation is given by $\delta_{\mathrm{b}}=\varepsilon_{\mathrm{b}} L_{\mathrm{b} . \mathrm{g}}$, in the case of the strain measurements, being $\varepsilon_{\mathrm{b}}$ the bolt strain and $L_{\mathrm{b} . \mathrm{g}}$ the bolt grip length. The results are alike for both series, which means that the measuring bracket that is much simpler to attach can be used to assess the bolt elongation behaviour in future tests.

Bolts M16 and M20 used in series WT7 and WT57 have not been tested.

Table 2 summarizes the average relevant characteristics for the tested bolts. Usually, for the bolts, the following parameters are measured: Young modulus, ultimate or tensile stress, $f_{\mathrm{u}}$ and ultimate strain, $\varepsilon_{\mathrm{u}}$.

\subsubsection{Tension tests of the structural steel}

The test programme included two different steel grades: S355 and S690. According to the European Standards EN 10025 [18] and EN 10204 [19], the steel qualities are S355J0 (ordinary steel) and N-A-XTRA M70 (high-strength steel for plates), respectively. Table 3 summarizes the chemical composition for the two steel grades.

The coupon tension testing of the structural steel material was performed according to the RILEM procedures [20]. The plate coupon specimens were of a standard type for flat materials and were of full thickness of the product [20]. Fig. 7 depicts the test arrangement for the standard tensile test. The experiments were driven under displacement control. The nominal stress-engineering strain relation for

\section{Table 2}

Average characteristic values for the bolts

\begin{tabular}{llllrl}
\hline Bolt grade & Type & Group & $E(\mathrm{MPa})$ & $f_{\mathrm{u}}(\mathrm{MPa})$ & $\varepsilon_{\mathrm{u}}$ \\
\hline \multirow{2}{*}{8.8} & FT & 1 & 216,942 & 968.36 & 0.20 \\
& ST & 2 & 221,886 & 919.91 & 0.13 \\
10.9 & FT & 3 & 217,060 & 1196.37 & 0.14 \\
& ST & 4 & 217,824 & 1165.97 & 0.11 \\
\hline
\end{tabular}


Table 3

Chemical composition of the structural steels according to the European standards

\begin{tabular}{llllllll}
\hline & $\% \mathrm{C} \max$. & $\% \mathrm{Mn} \max$. & $\% \mathrm{Si} \max$. & $\% \mathrm{P} \max$. & $\% \mathrm{~S} \max$. & $\% \mathrm{~N} \max$. & $\% \mathrm{CEV} \max$. \\
\hline S355J0 & 0.20 & 1.60 & 0.55 & 0.040 & 0.045 & 0.009 & 0.40 \\
N-A-XTRA M70 & 0.20 & 1.60 & 0.80 & 0.020 & 0.010 & - & 0.48 \\
\hline
\end{tabular}

the web and flange strips is represented in Fig. 8, for one of the tested strip-coupons. The four typical regions of the stress-strain curve of a low carbon structural steel are very clear: linear elastic region, yield plateau, strain hardening region and strain softening or necking portion, after the maximum load has been reached.

The average characteristics are set out in Table 4 . In this table, the values for the Young modulus, $E$, the strain hardening modulus, $E_{\mathrm{st}}$ the static yield and tensile stresses, $f_{\mathrm{y}}$ and $f_{\mathrm{u}}$ the yield ratio, $\rho_{\mathrm{y}}=f_{\mathrm{y}} / f_{\mathrm{u}}$ the strain at the strain hardening point, $\varepsilon_{\mathrm{st}}$ the uniform strain, $\varepsilon_{\mathrm{uni}}$ and the ultimate strain, $\varepsilon_{\mathrm{u}}$ are given. The stress values indicated in the table correspond to the static stresses, which are the stress values obtained at zero strain rate, i.e. during a hold on of the deformation driven experiment. It has been observed that the static stresses were reached after a hold on of circa $1 \mathrm{~min}$. The total hold on lasted for $3 \mathrm{~min}$. The yield ratio gives an idea on the material ductility. Gioncu and Mazzolani suggest that a good ductility is ensured if $0.5 \leq \rho_{\mathrm{y}} \leq 0.7$ [21]. High strength steel grades with $\rho_{\mathrm{y}}>0.9$ show a rather poor structural ductility [21]. That is the case of the steel grade S690 (Table 4). In the authors' opinion, these values are rather conservative. Eurocode 3 [11] indicates that a good material ductility is guaranteed if $\rho_{\mathrm{y}} \leq 0.83$ (recommended value for steel grades up to S460). The assurance of a good material ductility does not necessarily imply that the whole structure is ductile. The structural ductility depends on the yield ratio but specially on the structural discontinuities.

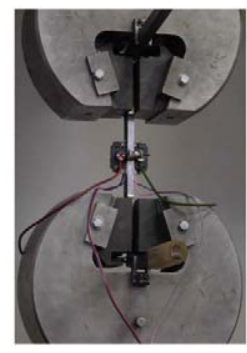

(a) Test setup.

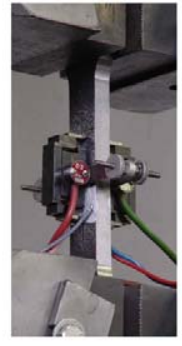

(b) Detail of the

extensometer.

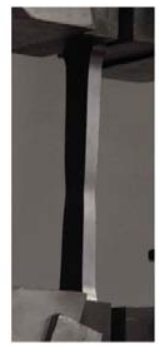

(c) Necking of the

coupon.

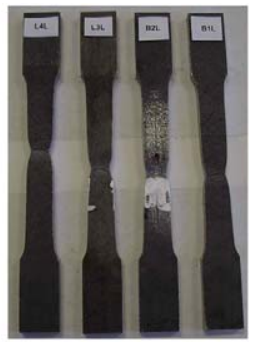

(d) S355 coupons

after failure.

Fig. 7. Tensile coupon tests. 


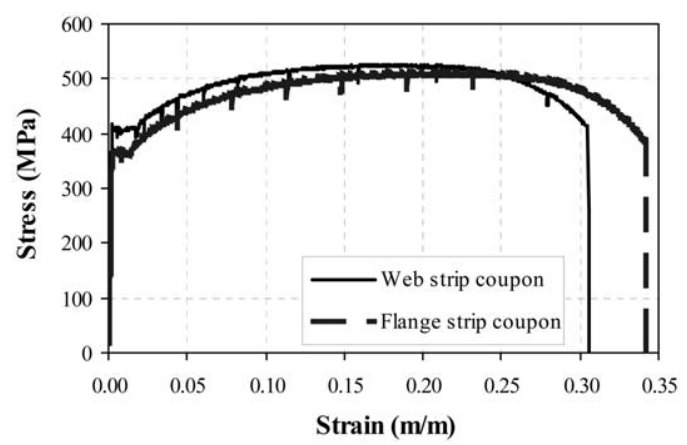

(a) Steel grade S355.

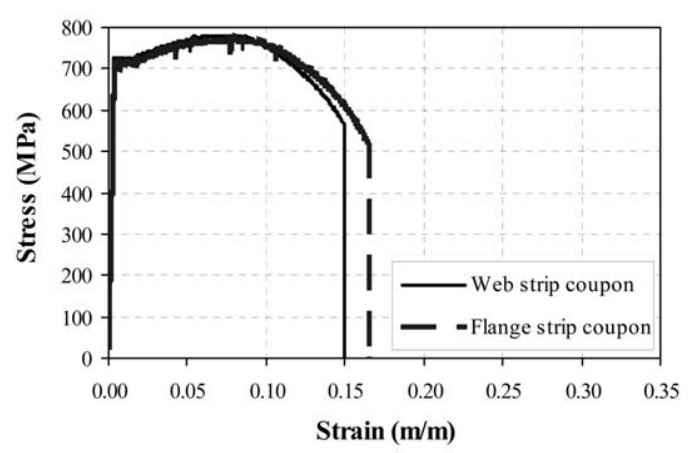

(b) Steel grade S690.

Fig. 8. Nominal stress-engineering strain relation.

\subsection{Testing procedure}

The specimens were subjected to monotonic tensile force, which was applied to the webs that were clamped to the testing machine (Schenck, maximum test load $600 \mathrm{kN}$, maximum piston stroke $\pm 125 \mathrm{~mm}$ ) as shown in Fig. 9. The tests were carried out under displacement control with a speed of $0.01 \mathrm{~mm} / \mathrm{s}$ up to collapse of

\section{Table 4}

Average characteristic values for the structural steels

\begin{tabular}{lllllllllll}
\hline Steel grade & Strip & $\#$ & $E(\mathrm{MPa})$ & $\begin{array}{l}E_{\mathrm{st}} \\
(\mathrm{MPa})\end{array}$ & $f_{\mathrm{y}}(\mathrm{MPa})$ & $f_{\mathrm{u}}(\mathrm{MPa})$ & $\rho_{\mathrm{y}}$ & $\varepsilon_{\text {st }}$ & $\varepsilon_{\text {uni }}$ & $\varepsilon_{\mathrm{u}}$ \\
\hline \multirow{2}{*}{ S355 } & Web & 2 & 209,211 & 2145 & 391.54 & 493.80 & 0.793 & 0.019 & 0.163 & 0.300 \\
& Flange & 2 & 209,856 & 2264 & 340.12 & 480.49 & 0.708 & 0.015 & 0.224 & 0.361 \\
\multirow{2}{*}{ S690 } & Web & 2 & 208,895 & 2201 & 706.31 & 742.96 & 0.950 & 0.018 & 0.082 & 0.160 \\
& Flange & 2 & 204,462 & 2495 & 698.55 & 741.28 & 0.940 & 0.014 & 0.075 & 0.174 \\
\hline
\end{tabular}




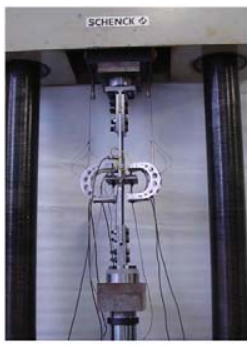

(a) Unstiffened specimen.

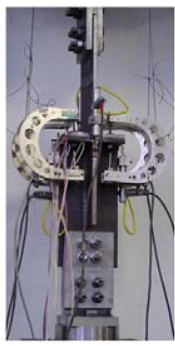

(b) Stiffened specimen

with T-stubs orientated at

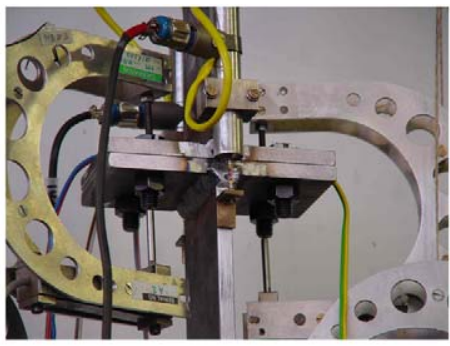

(c) Detail of the measuring devices.

$90^{\circ}$.

Fig. 9. Test set up.

the specimens. Two different collapse modes were observed, as explained below in the text: (i) fracture of the bolts and (ii) cracking of the flange near the weld toe.

The gap of the flanges was measured at opposite sides of the specimen, in the centreline of the webs by means of Linear Variable Displacement Transducers (LVDTs). The bolt elongation was measured with a measuring bracket that was removed prior to collapse, as before, so that it was not damaged. In some of the specimens, internal strain gauges similar to those used in the tension tests were attached to the bolt. Strain gauges TML (maximum strain $30000 \mu \mathrm{m} / \mathrm{m}$ ) were used to monitor strains in the flange. Due to cost restrictions, not all specimens have been instrumented with strain gauges. For illustration, Fig. 10 shows the instrumentation of some of the specimens.

Before installation of the specimens into the testing machine, the dimensions of the plates were recorded and the bolts were hand-tightened and measured. The specimen was then placed into the machine and aligned, so that the clamping devices were centred with respect to the webs. The bolts were then fastened by using an ordinary spanner $\left(45^{\circ}\right.$ turn) and measured. The measurement devices and strain gauges, if any, were then connected. The test itself then started with loading of the specimen up to $2 / 3 F_{\mathrm{Rd}}$, which corresponds to the theoretical elastic limit. $F_{\mathrm{Rd}}$ is determined according to Eurocode 3 [11]. Complete unloading followed on and the specimen was then reloaded up to collapse. In this third phase, the test was interrupted at the load levels of $2 / 3 F_{\mathrm{Rd}}, F_{\mathrm{Rd}}$, at the knee-range and after this level each $6 \mathrm{~min}$, equivalent to an actuator displacement of $3.6 \mathrm{~mm}$. The knee-range of the $F-\Delta$ curve corresponds to the transition from the stiff to the soft part. The hold on of the test lasted for $3 \mathrm{~min}$ and intended to record the quasi-static forces.

Regarding the stiffened specimens, the former load levels were taken as equal to the parent unstiffened cases. For the rotated configurations, the lower hydraulic actuator was rotated $90^{\circ}$ so that the T-element was orientated at a right angle to the upper element (Fig. 9b). 


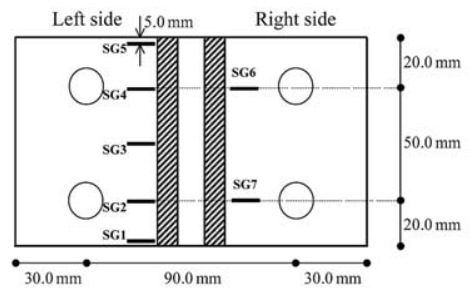

(a) Specimens WT1b/c/d/h, WT51a.

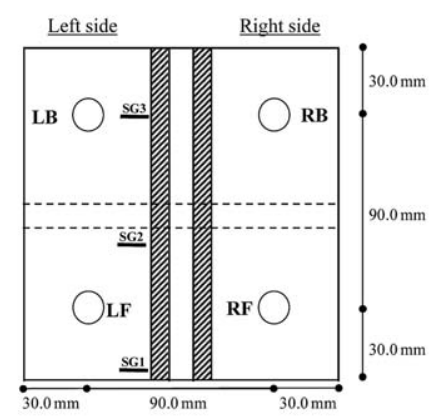

(i) Upper profile.

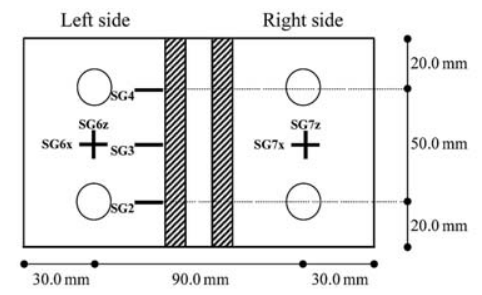

(b) Specimen WT51b.

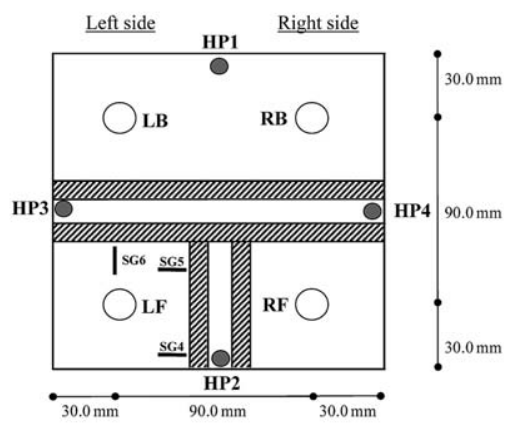

(ii) Lower profile.

(c) Specimen WT64Bb.

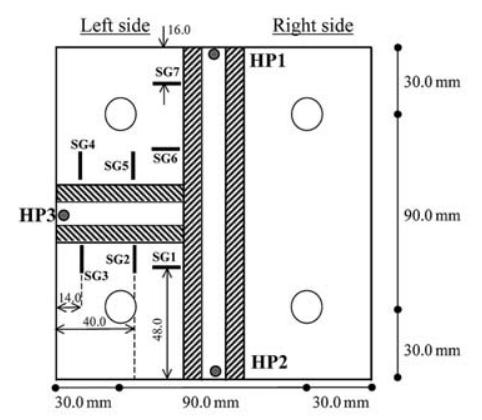

(d) Specimen WT64C (upper profile; lower

profile not instrumented).

Fig. 10. Instrumentation of some of the tested specimens (SG: strain gauge; L: left; R: right; B: bolt; HP: LVDT).

\subsection{Aspects related to the welding procedure}

In this type of T-stub assembly, two plates, web and flange, are welded together by means of a continuous $45^{\circ}$-fillet weld. The fillet welds were done in the shop in 
a down-hand position. The procedure involved manual metal arc welding that uses a consumable electrode. Three main zones can be identified after the welding process [22]: the weld metal (WM), the heat affected zone (HAZ) and the base metal (BM), which is the part of the parent plate that is not influenced by the heat input. The HAZ is the portion of the plate on either side of the weld affected by the heat in which metal suffers thermal disturbances and therefore structure modifications that may include recrystallization, refining and grain growth [23]. The hot WM causes the plate to bend up due to shrinkage during cooling down and so considerable force is exerted to do this [23]. Residual stresses can then be expected in the HAZ. Obviously, this will influence the overall behaviour of the connection.

The composition of the WM deposited with the electrode compared to that of the $\mathrm{BM}$ is of great importance, since this will naturally alter the properties of the steel at and near the weld toe [23]. For each steel quality there are often a large number of electrode types to choose from. In this test programme two different types of carbon steel covered electrodes were used: rutile and basic [24] - Table 5 . The distinction between them lies in the type of covering that results in different performances. Rutile electrodes have high titanium oxide content and produce easy striking with a stable arc and low spatter. They are commonly known as generalpurpose electrodes. The mechanical strength is generally classed as moderate. This type of consumable normally has high hydrogen content (higher than $10 \mathrm{ml} / 100 \mathrm{~g}$ all-WM). Basic electrodes offer improved mechanical properties and superior weld penetration. The mechanical strength is generally classed as good to high and the resistance to cracking is enhanced. They have a high proportion of calcium carbonate and calcium floride in the coating, which makes it more fluid than rutile coatings and also fast freezing. The hydrogen content is generally lower, which reduces the cracking problem.

Table 5 summarizes the main characteristics of the various electrodes. The classification indicated in the table complies with the European standard EN 499 [25]. Regarding this classification standard, the first two digits designate the minimum yield strength of the deposited WM and also refer to the limit boundaries of the tensile strength and minimum elongation of the WM. For instance, the Kardo electrode (E35) has a minimum yield stress of $350 \mathrm{MPa}$ (measured value: $396 \mathrm{MPa}$ ), the tensile strength varies between 440 and $570 \mathrm{MPa}$ (measured value: $453 \mathrm{MPa}$ )

Table 5

Characteristics of the electrodes and mechanical properties of the WM deposited

\begin{tabular}{|c|c|c|c|c|c|c|c|c|c|c|}
\hline \multirow[t]{2}{*}{ Brand name } & \multirow[t]{2}{*}{ Type } & \multirow[t]{2}{*}{ Classif. (EN 499) } & \multicolumn{6}{|c|}{ Chemical composition } & \multicolumn{2}{|c|}{ Actual mech. prop. } \\
\hline & & & $\% \mathrm{C}$ & $\% \mathrm{Mn}$ & $\% \mathrm{Si}$ & $\% \mathrm{P}$ & $\% \mathrm{~S}$ & $\% \mathrm{Ni}$ & $f_{\mathrm{y}}(\mathrm{MPa})$ & $f_{\mathrm{u}}(\mathrm{MPa})$ \\
\hline Cumulo & Rutile & E38 O R12 & 0.06 & 0.50 & 0.30 & - & - & - & Not provi & ded. \\
\hline Conarc 51 & Basic & E42 4 B12 H5 & \multicolumn{6}{|c|}{ Not provided. } & \multicolumn{2}{|c|}{ Not provided. } \\
\hline Kardo & Basic & E35 4 B32 H5 & 0.016 & 0.30 & 0.21 & 0.010 & 0.008 & 0.03 & 396 & 453 \\
\hline Conarc $70 \mathrm{G}$ & Basic & E55 4 B32 H5 & 0.06 & 1.2 & 0.4 & 0.014 & 0.009 & 1.0 & 600 & 655 \\
\hline
\end{tabular}


Table 6

Type of electrode used in the tests

\begin{tabular}{llllll}
\hline Test ID & Electrode & Test ID & Electrode & Test ID & Electrode \\
\hline WT1a/b/c & Cumulo & Series WT2 & Kardo & Series WT61 & Kardo \\
WT1d & Conarc 51 & Series WT4 & Kardo & Series WT64 & Kardo \\
WT1e/f & Cumulo & Series WT51 & Conarc 70G & Series WT7 & Kardo \\
WTg/h & Kardo & Series WT53 & Conarc 70G & Series WT57 & Conarc 70G \\
\hline
\end{tabular}

and a minimum elongation of $22 \%$. The latter value decreases as the strength of the WM increases [25], thus reducing the deformation capacity of the weld.

Table 6 lists the electrodes used in the welding of each specimen. Clearly, the Kardo and the Conarc $70 \mathrm{G}$ are the most utilized electrode types. These are soft, low hydrogen electrodes. The experiences on the consumable performance were carried out in test series 1. Fig. 11 shows the influence of the deposited WM on the global behaviour of the eight specimens from series WT1. Essentially, such behaviour mainly depends on the mismatch in mechanical properties between the three different zones and the hydrogen content [22,23]. In the elastic range, the deformation behaviour is not too much dependent on the WM properties. However, when the connection is plastically deformed, the choice of the electrode type becomes crucial. The graphs show that the deformation capacity of the joint is greatly influenced by the deposited WM mechanical properties. Both Cumulo and Conarc 51 electrodes induced an early cracking of the plates at the HAZ, limiting the deformation capacity of the T-stub and did not allow for the effective use of the bolts (Figs. 11 and $12 \mathrm{a}-\mathrm{c}$ ). Also, the scatter of the responses was not acceptable (Fig. 11a). Note that the load-carrying behaviour of WT1f deviates even more from the remaining tests because, by mistake, the weld throat thickness was 8.0 $\mathrm{mm}$ instead of the specified value of $5.0 \mathrm{~mm}$. The electrode that provided the best ductility to the overall connection (steel grade S355) is the Kardo (Figs. 11 and 12). It was therefore the most suitable consumable and was used in the rest of the specimens to weld the plates. This electrode is classified as an evenmatch electrode as the nominal properties of the WM and the BM are identical.

Finally, regarding the welding of the plates made up of S690, the electrode Conarc $70 \mathrm{G}$, specified by the distributor as the most suitable for that steel quality, guaranteed a performance identical to the Kardo electrode for S355.

\section{Test results}

\subsection{Failure modes and general characteristics of the overall behaviour of the test specimens}

The deformation capacity of a bolted T-stub connection made up of welded plates primarily depends on the plate/bolt strength ratio and the weld resistance that is associated to the consumable type and properties. Failure is eventually governed by brittle fracture of the bolts or the welds, or cracking of the plate material 


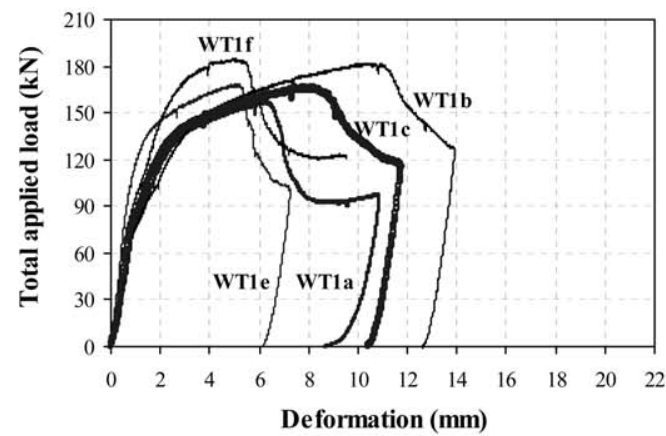

(a) Cumulo electrode (rutile).

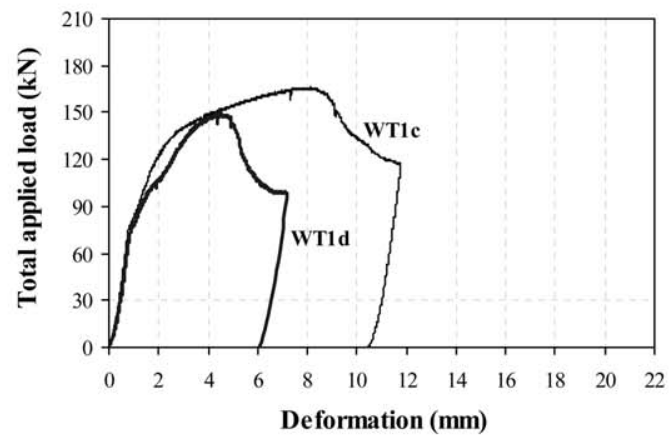

(b) Conarc 51 and cumulo electrodes (basic and rutile, respectively).

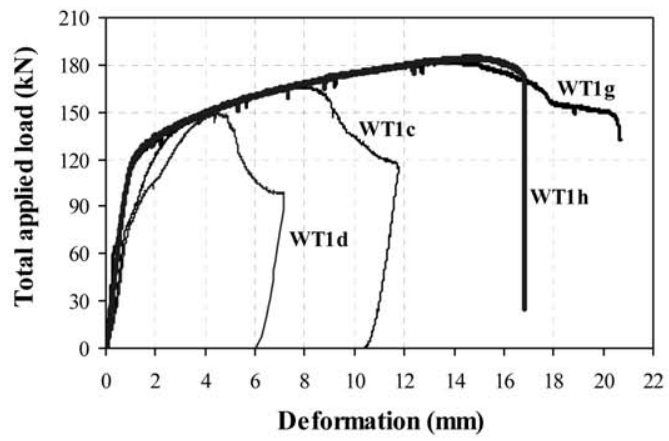

(c) Kardo electrode (basic).

Fig. 11. Performance of the different electrode types used for steel grade S355. 


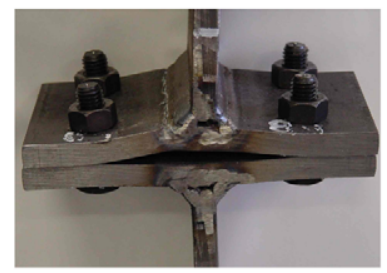

(i) Deformation at failure (WT1e).

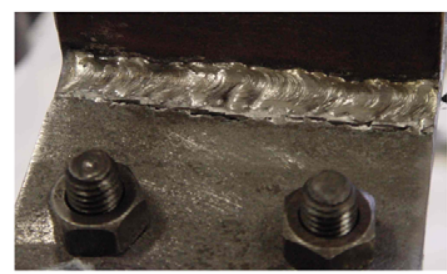

(ii) Detail of the typical crack (WT1a).

(a) Cumulo electrode (rutile).

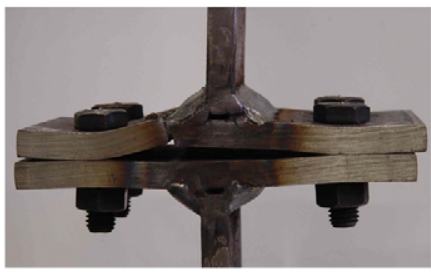

(i) Deformation at failure.

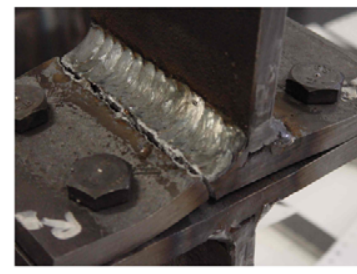

(ii) Detail of the crack.

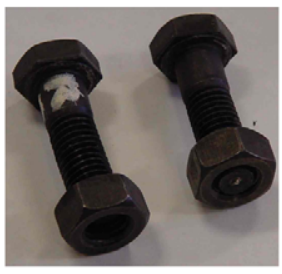

(iii) Detail of the bolts (no bending deformations)

(b) Cumulo electrode (rutile) and $a_{w}=8.0 \mathrm{~mm}$ (WT1f).

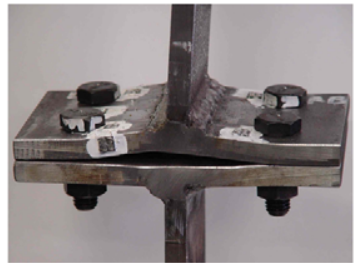

(c) Conarc 51 electrode (basic) (WT1d).

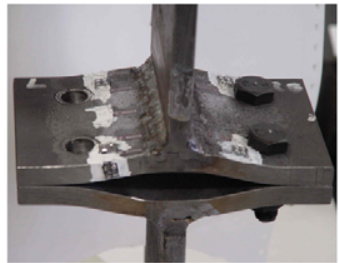

(d) Kardo electrode (basic) (WT1h).

Fig. 12. Illustration of the specimens from series WT1 after failure for comparison of the effect of the deposited WM with different electrode-types.

near the weld toe. Most of the tested specimens failed by tension rupture of the bolts after bending deformation of the flange. The degree of plastic deformation of the flange depends first and foremost on the geometric characteristics of the connection and the mechanical properties of the elements. However, the collapse of some specimens was due to cracking of the plate material in the HAZ.

In this T-stub assembly type, the collapse mode involving rupture of the plate was also affected by residual stresses and modified microstructure in the HAZ. This led to a reduction of the ultimate material strain with respect to the unaffected material and thus to an earlier failure of the whole connection. It was also 
observed that the extent of the properties variations in the HAZ, which were inherent to the welding procedure, were highly dependent on the electrode type and the hydrogen content, in particular.

The observed failure modes involved combined bending and tension bolt fracture (type-A) in 19 specimens, stripping of the nut threads bolt fracture (type-B) in 1 specimen (WT57_M16), cracking of the plate material in the HAZ (type-C) for 10 specimens and combined failure modes A and $\mathrm{C}$ (type-AC) in the remaining cases. Notice that the stiffened specimens failed in a combined bending and tension bolt fracture mode. Table 7 summarizes the collapse modes of the several tests.

Depending on the failure mode and naturally on the connection configuration, similar behaviour was observed between related specimens. The most significant characteristic describing the overall behaviour of the connection is the $F-\Delta$ response. Fig. 13 plots the load-carrying behaviour of five selected examples that illustrate the four collapse modes. For the parallel T-stub elements specimens, the deformation corresponds to the average value measured by the two LVDTs at each specimen. For specimen WT64B that included a stiffener and where the two Tstubs are orientated at right angles, the results for LVDTs HP1 and HP2 (see Fig. 10c) are shown. Fig. 14 depicts the five above specimens at failure conditions.

First, consider specimens WT1g, WT7_M16 and WT61b, which exhibit failure modes type-AC, type-C and type-A, respectively (Fig. $14 \mathrm{a}-\mathrm{c}$ ). The $F-\Delta$ curves are characterized by an elastic branch, with slope $k_{\mathrm{e} .0}$, that develops until yielding of the flange begins. A loss of stiffness follows on and at a certain load level a quasilinear branch with slope $k_{\mathrm{pl} .0}$ then arises. This post-limit region is longer for specimens WT1g and WT7_M16 that developed large bending deformations of the flange, when compared to test WT61b. For this specimen, which was stiffened one side, the bolts at the stiffened side determined the collapse. Therefore, at failure, there was a sudden drop of load with constant deformation, which characterizes a brittle failure type. Regarding specimen WT7_M16, the failure mechanism was very ductile and after the maximum load was reached, at a deformation of about $12 \mathrm{~mm}$, the drop of load was very smooth and proceeded with increasing deformation between the flanges. This test was stopped at $\Delta \approx 16 \mathrm{~mm}$ because the

Table 7

Observed failure modes

\begin{tabular}{|c|c|c|c|c|c|c|c|c|}
\hline \multirow[t]{2}{*}{ Test ID } & \multicolumn{2}{|c|}{ Failure mode } & \multirow[t]{2}{*}{ Test ID } & \multicolumn{2}{|c|}{ Failure mode } & \multirow[t]{2}{*}{ Test ID } & \multicolumn{2}{|c|}{ Failure mode } \\
\hline & Type & $\#$ & & Type & $\#$ & & Type & $\#$ \\
\hline \multirow{3}{*}{ WT1 } & A & 1 & WT4A & A & 2 & WT64B & A & 2 \\
\hline & $\mathrm{C}$ & 6 & WT4B & A & 1 & WT64C & A & 1 \\
\hline & $\mathrm{AC}$ & 1 & WT51 & A & 2 & WT7_M12 & A & 1 \\
\hline \multirow[b]{2}{*}{ WT2A } & A & 1 & WT53C & A & 1 & WT7_M16 & $\mathrm{C}$ & 1 \\
\hline & $\mathrm{AC}$ & 1 & WT53D & A & 1 & WT7_M20 & $\mathrm{C}$ & 1 \\
\hline \multirow{3}{*}{ WT2B } & A & 1 & WT53E & $\mathrm{A}$ & 1 & WT57_M12 & A & 1 \\
\hline & $\mathrm{AC}$ & 1 & WT61 & A & 2 & WT57_M16 & B & 1 \\
\hline & & & WT64A & A & 1 & WT57_M20 & $\mathrm{AC}$ & 1 \\
\hline
\end{tabular}




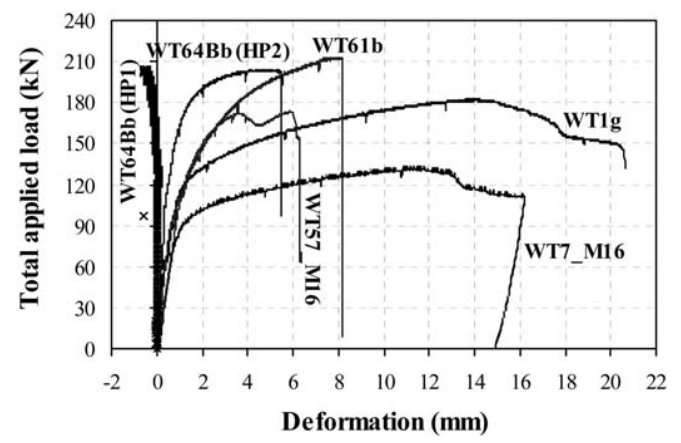

Fig. 13. Force-deformation characteristics of some of the tested specimens.

webs started to bend and twist excessively and that would damage the equipment. If the test had continued, the behavioural tendency would have been the same. Finally, with respect to specimen WT1g that exhibited a combined failure mechanism, the maximum load was reached for a deformation of $14 \mathrm{~mm}$, after which it started decreasing. This decrease was smooth and corresponded to the beginning of cracking of the flange plate close to the weld toe. Eventually, at $\Delta \approx 20 \mathrm{~mm}$, there was a sudden drop of load that coincided with the bolt fracture. Notice that bolt rupture took place at opposite side of plate cracking. Apparently, a larger deformation capacity would have been expected for specimen WT7_M16, when compared to WT1g, because the bolt did not govern the collapse. However, since the T-stub width tributary to a bolt row was higher in specimen WT7_M16, smaller deformation capacity was expected [15].

Concerning specimen WT64Bb, it tried to mimic the actual configuration of the tension side of a bolted connection: elements orientated at right angles, one $\mathrm{T}$ element stiffened and the other unstiffened. When this assembly was subjected to a tensile force, the plates became in contact except at the stiffener-web contact, as clearly shown in Fig. 14d. Therefore, the $F-\Delta$ response depicted in Fig. 13 shows that the two flanges are opening at the stiffener side (HP2) and closing at the opposite side (HP1). The characteristics of the curve for LVDT HP2 are very similar to those described for WT61b, where also bolt fracture at the stiffener side governed the ultimate condition.

Finally, type-B failure that occured in specimen WT57_M16 (and is not common) is a brittle rupture mode. The specimen at collapse is illustrated in Fig. 14e and the corresponding load-carrying behaviour is shown in the graph from Fig. 13.

\subsection{Experimental results for the unstiffened test specimens}

\subsubsection{Reference test series WT1}

Test series WT1 comprehends eight specimens that differ in the electrode type used in the welding procedure, as explained above. It has been shown previously that the Kardo electrode seems the most suitable in terms of overall connection 


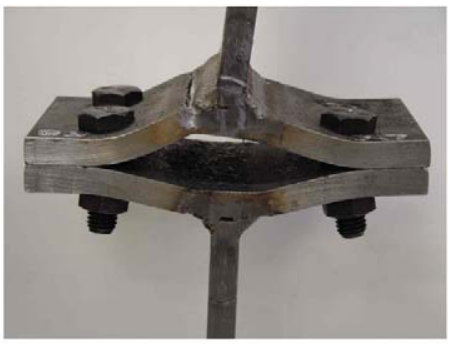

(a) Specimen WT1g (failure type-AC).

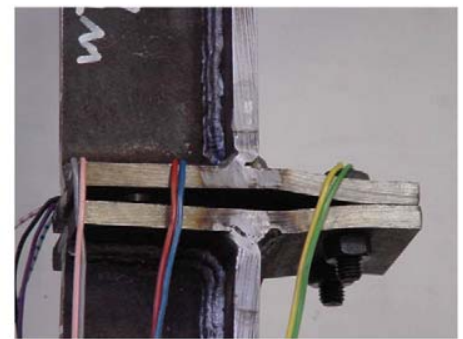

(c) Specimen WT61b (failure type-A).

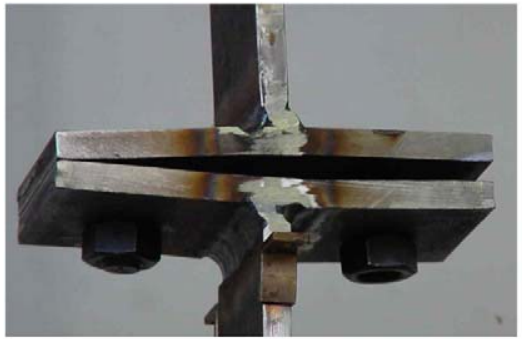

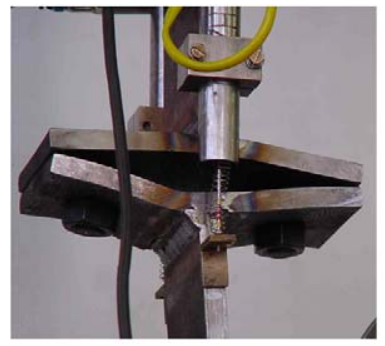

(b) Specimen WT7_M16 (failure type-C).

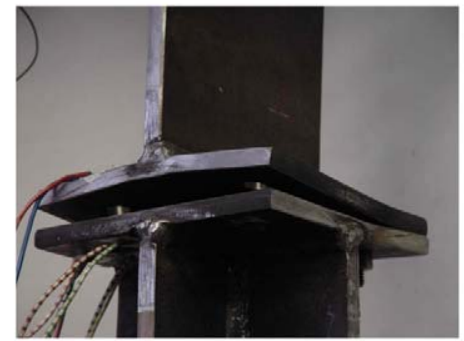

(d) Specimen WT64Bb (failure type-A).

(e) Specimen WT57_M16 (failure type-B).

Fig. 14. Specimens at failure.

performance (Fig. 11). For further analysis consider then specimens WT1g/h whose collapse was determined by bolt fracture with some damage of the plate in the HAZ in the first case, as well (Figs. 12d and Fig. 14a).

The load-carrying behaviour of the above specimens is compared with the Eurocode 3 [11] predictions of elastic stiffness and plastic resistance in Fig. 15 (results in Table 8). Notice that the experimental $F-\Delta$ curves depicted throughout the paper correspond to the third part of the test-reloading up to collapse (cf. Section 2.3). Eurocode 3 [11] underestimates both properties - see also Table 9. The experimental elastic stiffness is computed by means of a regression analysis of the unloading portion of the $F-\Delta$ curve (which is not traced in the graphs). By com- 


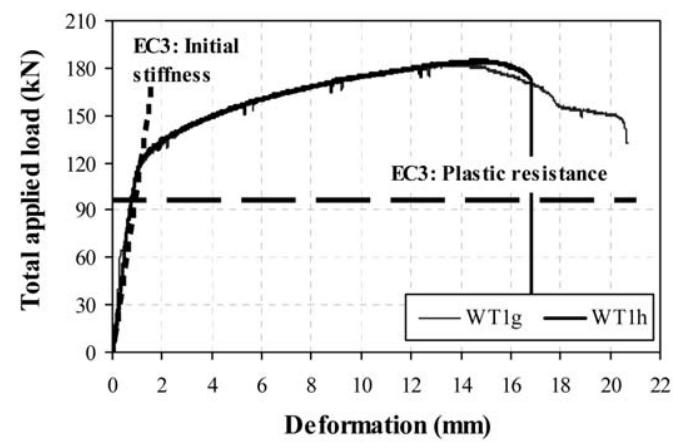

Fig. 15. Experimental load-carrying behaviour of specimens WT1g/h and comparison with Eurocode 3 (EC3) predictions.

paring the results, there is a ratio between the experiments and the code predictions of 1.25 and 1.34 for WT1g and WT1h, respectively. Also, if the lower bound of the knee-range of the $F-\Delta$ curve is compared with $F_{\mathrm{Rd}}$ as predicted by Eurocode 3 [11], deviations of 1.19 (WT1g) and 1.23 (WT1h) are observed.

The remaining characteristics of the $F-\Delta$ response (post-limit stiffness and deformation capacity, $\Delta_{\mathrm{u}}$ ) cannot be compared with any code provisions since it does not cover the post-limit behaviour. Table 9 sets out the values of maximum load, $F_{\max }$ post-limit stiffness (also determined by means of a regression analysis of the post-limit response) and the deformation capacity, taken as the deformation level corresponding to $F_{\max }$. The last three columns of this table indicate the values given by both LVDTs and their average value, as well. Table 9 summarizes the results for the eight tests, corroborating the above-mentioned scatter of results between the six initial specimens.

Figs. 16 and 17 show other results type also obtained in this test series. The results of the bolt elongation behaviour for specimen WT1h is given in Fig. 16. The graph does not apply up to collapse since the bolt deformation was measured

Table 8

Eurocode 3 predictions of initial stiffness and plastic resistance (evaluated using the average real dimensions of the specimens)

\begin{tabular}{lcclcl}
\hline Test series & $k_{\mathrm{e} .0}(\mathrm{kN} / \mathrm{mm})$ & $F_{\mathrm{Rd}}(\mathrm{kN})$ & Test series & $k_{\mathrm{e} .0}(\mathrm{kN} / \mathrm{mm})$ & $F_{\mathrm{Rd}}(\mathrm{kN})$ \\
\hline WT1 & 109.48 & 96.75 & WT53D & 98.54 & 216.15 \\
WT2A & 88.68 & 89.82 & WT53E & 96.40 & 215.74 \\
WT2B & 129.21 & 102.62 & WT57_M12 & 78.83 & 110.94 \\
WT4A & 181.98 & 164.62 & WT57_M16 & 82.97 & 148.44 \\
WT7_M12 & 86.60 & 80.89 & WT57_M20 & 83.85 & 159.47 \\
WT7_M16 & 89.09 & 80.05 & WT61 & 158.52 & 153.19 \\
WT7_M20 & 91.63 & 80.63 & WT64A & 192.84 & 172.85 \\
WT51 & 92.93 & 179.34 & WT64C & 214.48 & 182.45 \\
WT53C & 96.57 & 187.35 & & & \\
\hline
\end{tabular}




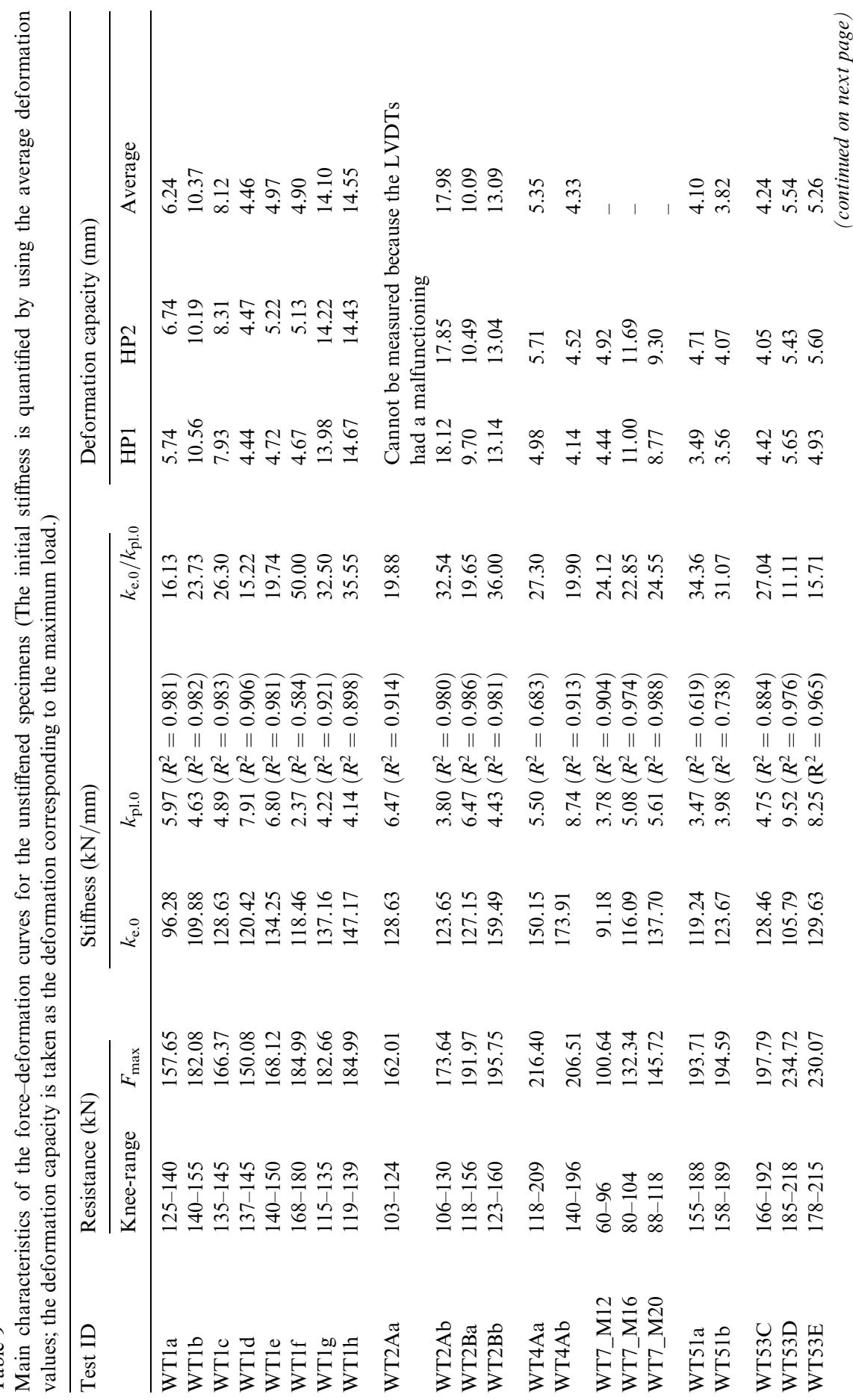




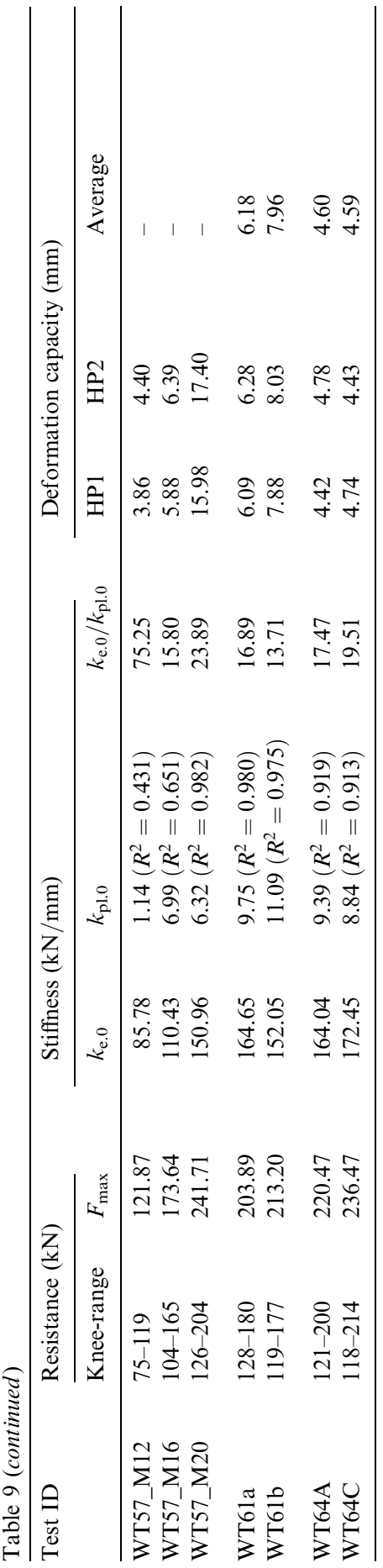




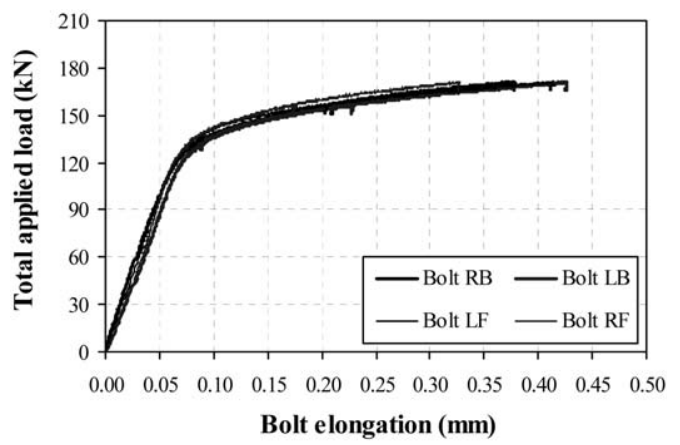

Fig. 16. Experimental results for the bolt elongation behaviour (specimen WT1h).

by means of the horseshoe device that was removed before the maximum load was reached. The graph shows that the results are alike for the four bolts and, consequently, the four curves are nearly indistinguishable. Specimen WT1h was also instrumented with strain gauges (see Fig. 10a). These were attached close to the

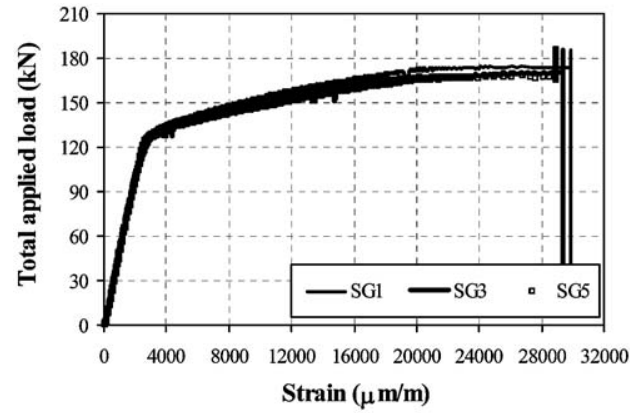

(a) Strain gauges SG1, SG3 and SG5.

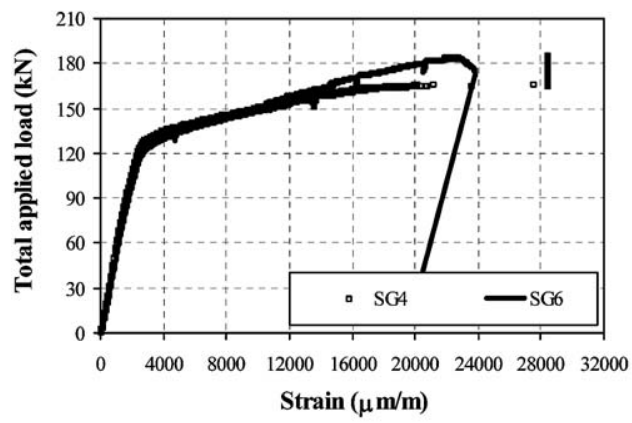

(b) Strain gauges SG4 and SG6.

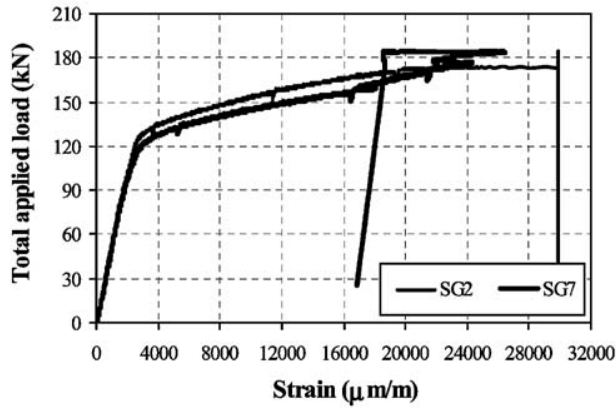

(c) Strain gauges SG2 and SG7.

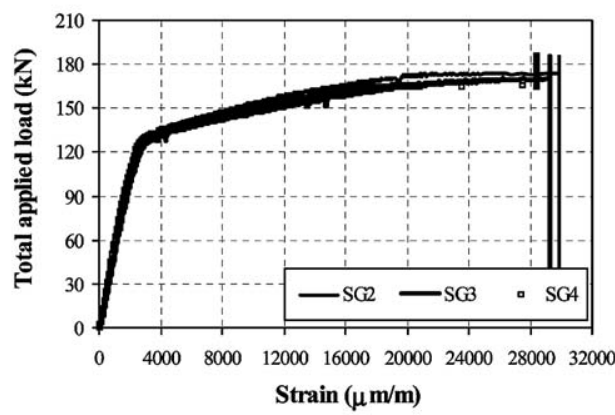

(d) Strain gauges SG2, SG3 and SG4.

Fig. 17. Experimental results for the flange strain behaviour (specimen WT1h). 
fillet weld, near the theoretical location of the expected yield line. The force-strain results are shown in Fig. 17. In particular, Fig. 17a compares the results for the edge strain gauges (SG1, SG5) and the one attached at mid length of the specimen (SG3). The results are very similar. Fig. 17b and c depict symmetry. The results are analogous but not exactly the same for symmetric strain gauges, since they may not be placed exactly on the same spot. Finally, Fig. 17d compares the strain results for the remaining strain gauges that are also alike.

\subsubsection{Influence of the weld throat thickness}

The second series of tests included the analysis of the influence of the fillet weld throat thickness, $a_{\mathrm{w}}$ on the overall behaviour. Bolt failure was still the determinant factor of collapse, though some damage in the HAZ was observed in specimens WT2Aa and WT2Ba. In these specimens the weld quality was inferior to the expected and this may explain such plate damage. Fig. 18a shows that if $a_{\mathrm{w}}$ decreases, the resistance slightly decreases, whilst the deformation capacity improves, with little variation of stiffness. On the other hand, if $a_{\mathrm{w}}$ increases, the deformation

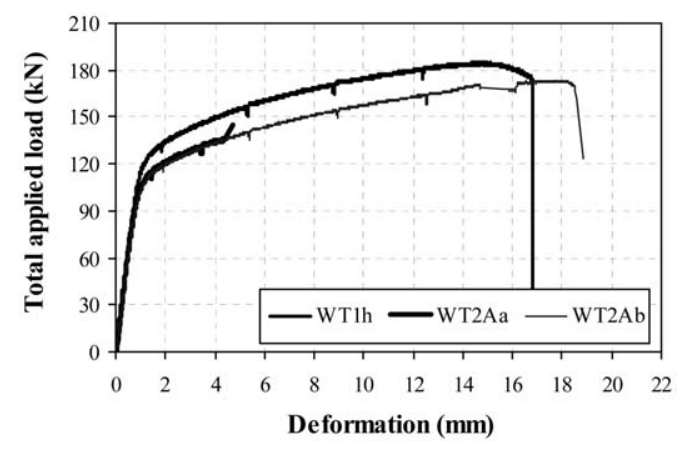

(a) Series WT2A: smaller weld throat thickness.

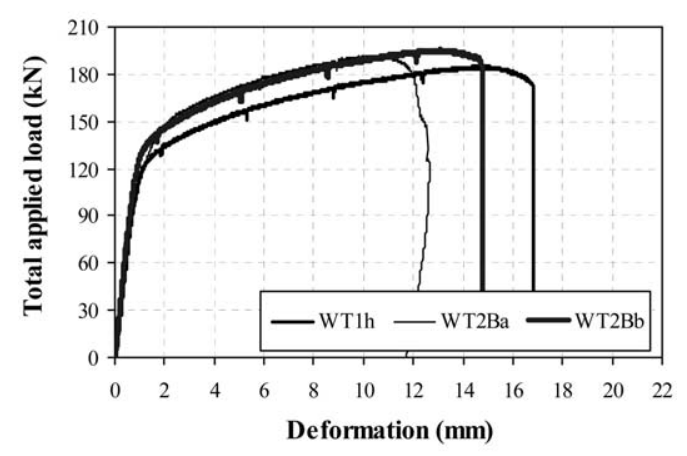

(b) Series WT2B: smaller weld throat thickness.

Fig. 18. Experimental load-carrying behaviour of specimen series WT2 and comparison with WT1h. 
capacity reduces, resistance increases and still small change on the slope of the two characteristic branches of the $F-\Delta$ curve (Fig. 18b). Tables 8 and 9 that set out the Eurocode 3 [11] predictions and the main (experimental) characteristics of the tests also confirm the above statements. Regarding the prediction of $k_{\mathrm{e} .0}$, it seems that Eurocode 3 [11] presents wider scatter in the values for different values of $a_{\mathrm{w}}$ than actually observed.

In series WT2Aa there was a malfunctioning of the LVDTs and there is only a record of the deformation behaviour until $\Delta \approx 4.5 \mathrm{~mm}$.

\subsubsection{Influence of the T-stub width}

The effect of the T-stub width is studied in test series WT4A, in terms of overall behaviour and failure mode. Fig. 19 compares the results for the two tests from this series with WT1h. The knee-range of the curves for WT4A occurs at higher load levels, which indicates that the yielding of the flange develops for higher strength values (see also Table 9). Similar statement is also valid for the maximum strength. With respect to the connection ductility, both Fig. 14 and Table 9 show that if the T-stub width increases, the deformation capacity decreases. When comparing specimens WT1g/h and WT4Aa/b, the reduction of $\Delta_{\mathrm{u}}$ is, in average, $66 \%$.

Bolt determined collapse in all cases. In particular, for WT4Aa, only bolt RB did not fail and for specimen WT4Ab, for which there was a record of the bolt elongation behaviour up to collapse (Fig. 20), the bolts on the left side were broken (Fig. 21-the specimen is rotated in this figure). In fact, the graph from Fig. 20 shows that the bolts on the right side yield smaller deformation than the others. It should be stressed that this measurement has only been carried out only in this specific specimen as an experience. Unfortunately, it was observed that the measuring brackets were damaged in the end and therefore they had to be replaced prior to collapse.

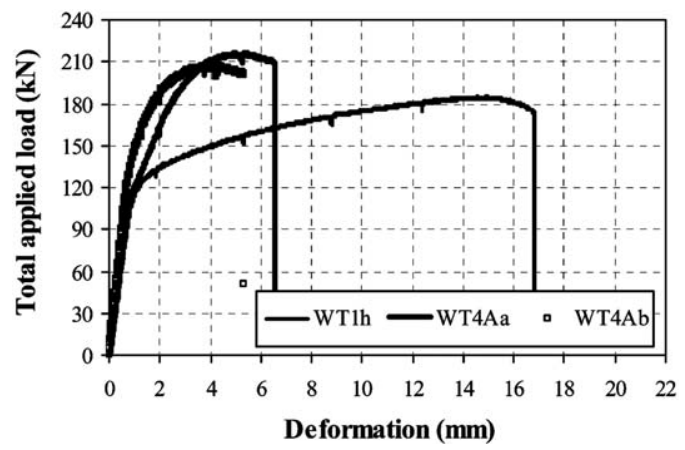

Fig. 19. Experimental load-carrying behaviour of specimen series WT4A and comparison with WT1h. 


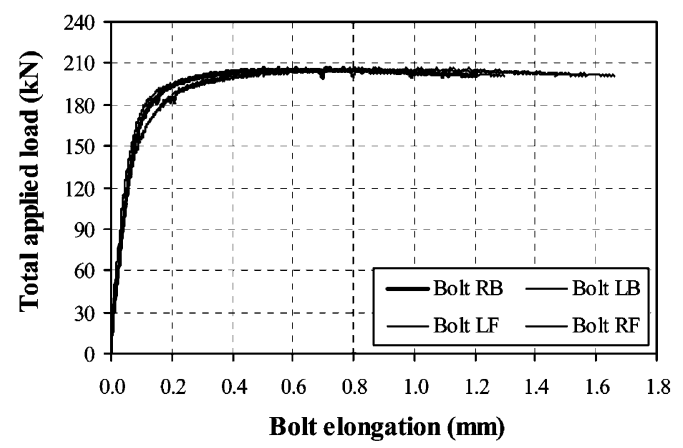

Fig. 20. Experimental results for the bolt elongation behaviour (specimen WT4Ab).

The plastic collapse mode for this series, computed with the nominal dimensions, is of type-1, but very close to the boundary limit of type- 2 . Type- 2 plastic mechanism is characterized by the formation of two plastic hinges at the flange-to-web connection (single curvature of the flanges) and the fracture of the bolts. And in fact, the $F-\Delta$ curve resembles more a type- 2 plastic mechanism rather than a type- 1 . Also, Fig. 21b shows that the bolts are highly deformed at collapse. In this figure, an unbroken bolt is shown and the combined bending and tension deformations are very clear.

Finally, Table 8 summarizes the Eurocode 3 [11] predictions of elastic stiffness and plastic resistance, showing that the increase of the T-stub width results in an amplification of both values. Table 9 indicates the principal characteristics of the experiments and corroborates the previous considerations.

\subsubsection{Influence of the bolt diameter}

Test series WT7 qualifies (and quantifies) the effect of the bolt diameter on the load-carrying behaviour of a T-stub (Fig. 22). Three bolt diameters were considered, maintaining the T-element geometry constant. Fig. 22 plots the results for

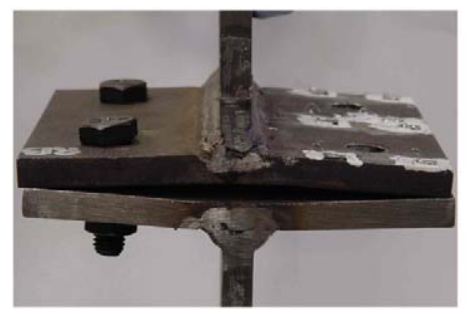

(a) Deformation at failure.

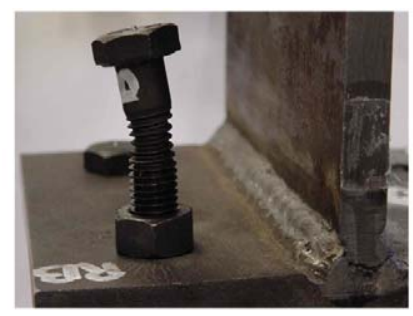

(b) Detail of an unbroken bolt after failure of

the connection.

Fig. 21. Specimen WT4Ab at collapse conditions. 


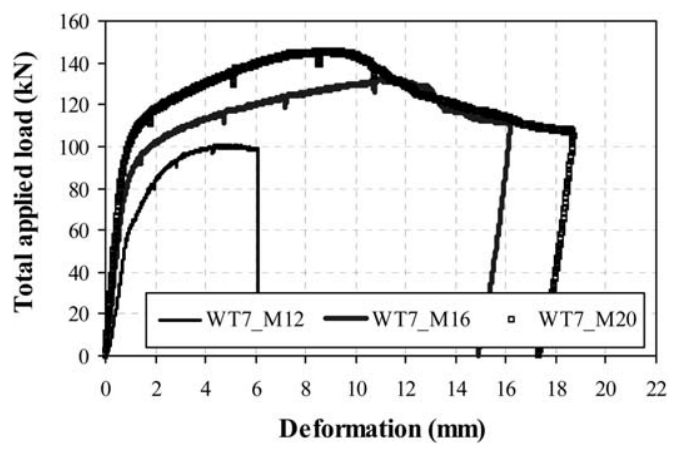

Fig. 22. Experimental load-carrying behaviour of specimen series WT7.

LVDT HP1 (at the shorter edge side) for future comparison with other test series. Clearly, as the bolt diameter increases, the resistance and stiffness increase, as well as deformation capacity. Surprisingly, if the deformation capacity of the connection is evaluated at the maximum load level, specimen WT7_M16 yields a higher value when compared to WT7_M20. However, the ductile branch after the commencement of collapse is longer in the latter case. These conclusions can also be taken from Tables 8 and 9. For illustration, Figs. 14d and 23 show the specimens at failure conditions.

Another comparison that can be performed with this test series (specimen WT7_M12, more specifically) and series WT4A relates to the influence of the number of bolts fastening the T-stub elements. Fig. 24 compares the $F-\Delta$ response, per bolt row, for the three specimens, and shows a good agreement. This means that the symmetric behaviour is valid. This graph also shows that for specimen WT7_M12 at a load level of $58 \mathrm{kN}$ some slippage occurred, resulting in a sharp decrease of stiffness in the response. Identical situation was observed in WT4Aa.

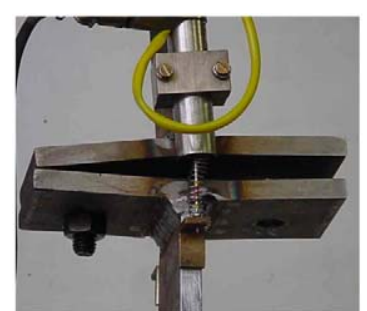

(a) Specimen WT7_M12.

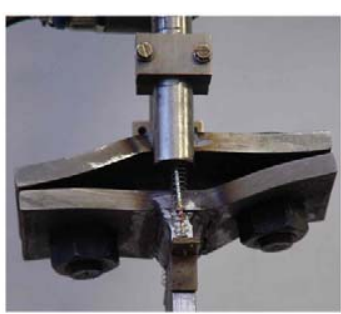

(b) Specimen WT7_M20.

Fig. 23. Deformation of specimens WT7_M12 and WT7_M20 at failure. 


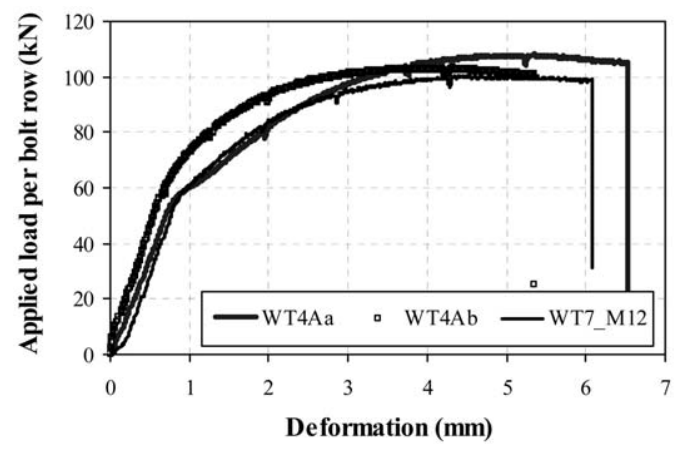

Fig. 24. Experimental load-carrying behaviour of specimen WT7_M12 and comparison with series WT4Aa (per bolt row).

\subsubsection{Influence of the steel grade and bolt type}

Test series WT51 comprehended the testing of two specimens geometrically identical to the original test series WT1 and whose T-stub elements are made up of high-strength steel S690. According to Eurocode 3 [11], these specimens exhibit a type-2 plastic mechanism. The load-carrying behaviour of both tests WT51 is compared with the original test WT1h in Fig. 25. As expected, the initial stiffness is nearly the same (Tables 8 and 9), the ultimate resistance is also identical (Table 9) since bolt governed collapse in the three cases and the deformation capacity is far reduced in series WT51 because the bolts were engaged in collapse of the specimen at an earlier stage. The knee-range of the $F-\Delta$ response of specimens WT51 develops for higher loads in comparison to WT1h. The slope of the post-limit part of these curves is lower than in the original case. Here, the single curvature of the flange was evident (Fig. 26) and the deformation of the flanges is far less than in series WT1 (see Fig. 12d, for instance). This is also clear in Fig. 27a where the strains for WT1h and WT51b are compared for SG3, on the same location in both specimens (Fig. 10a and b). Fig. 27b plots the force-strain results for the two T-

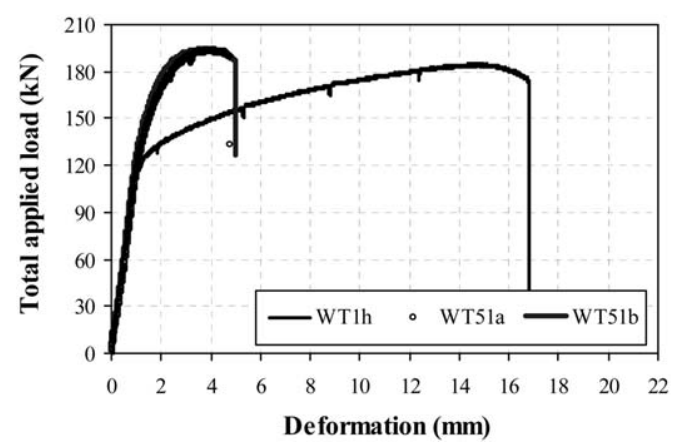

Fig. 25. Experimental load-carrying behaviour of specimen series WT51 and comparison with WT1h. 


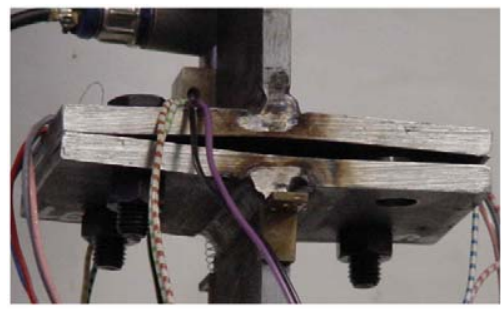

(a) Deformation at failure (WT51b).

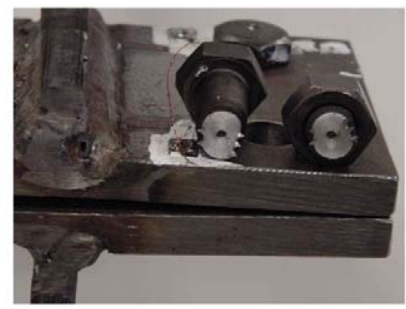

(b) Detail of a broken bolt (WT51a).

Fig. 26. Deformation of specimens WT51 at failure.

rosettes attached in specimen WT51b. It shows that the flange strain level there at collapse is rather low. Symmetry of results is also rather obvious.

Now, consider test series WT53 to assess the influence of the bolt type on the overall response. Naturally, since the actual bolt properties also varied (Table 2),

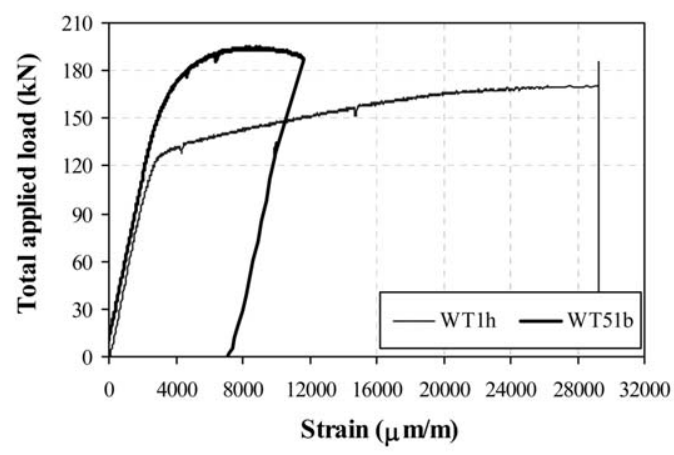

(a) Comparison of the results for SG3 in specimens WT1h and WT51b.

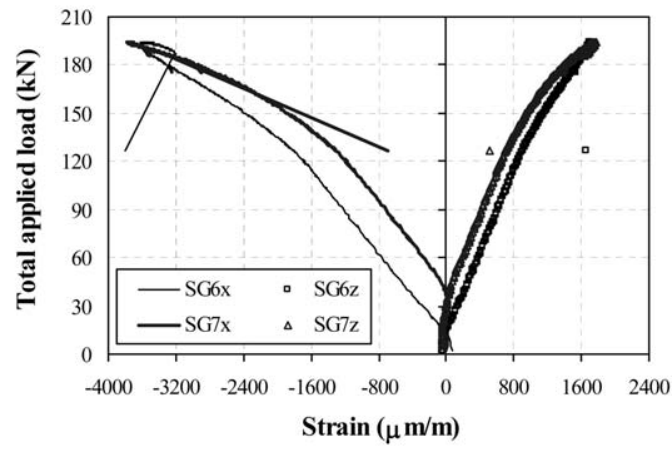

(b) Results for the rosettes.

Fig. 27. Experimental results for the flange strain behaviour (specimen WT51b). 


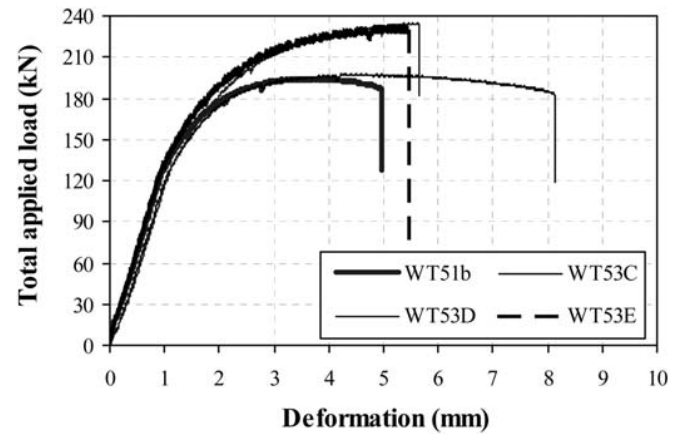

Fig. 28. Experimental load-carrying behaviour of specimen series WT53 and comparison with WT51b.

the global results include not only the effect of the bolt type (short- or long-threaded) but also their mechanical properties. Fig. 28 depicts the $F-\Delta$ response of identical T-stub elements connected by means of the four different M12 bolt types tested (cf. Section 2.2.1). The graphs show that if higher strength bolts are used (WT53D/E), since bolt determined failure in the four cases, the maximum load reached is also higher (see Tables 8 and 9). For the four specimens compared in this figure, the initial stiffness is identical because the Young modulus, which is one of the main parameters used in the computation of $k_{\mathrm{e} .0}$, is identical for the four bolt types (Table 2).

If bolt governs the failure mode of the T-stub, the overall deformation capacity mainly depends on the maximum elongation of the bolt, or, in other words, on their ultimate strain values. Table 2 shows that full-threaded bolts exhibit higher values of $\varepsilon_{\mathrm{u}}$ (though for bolt grade 10.9 that difference is smaller) and higher bolt grades exhibit smaller deformations, i.e. the failure type is more brittle. When taking into account the T-stubs WT51b and WT53C/D/E, the above considerations are still valid. Specimen WT53C is more ductile than the remaining since the fasteners were full-threaded M12 grade 8.8, even though the deformation level at $F_{\max }$ is lower (Table 9). For this specimen, the plateau that follows $F_{\max }$ is far longer than in the other cases (Fig. 28). Surprisingly, the deformation capacity for both tests WT53D/E that use bolt grade 10.9 is identical. These conclusions are also indicated in Table 9. Fig. 29 illustrates the four specimens after failure.

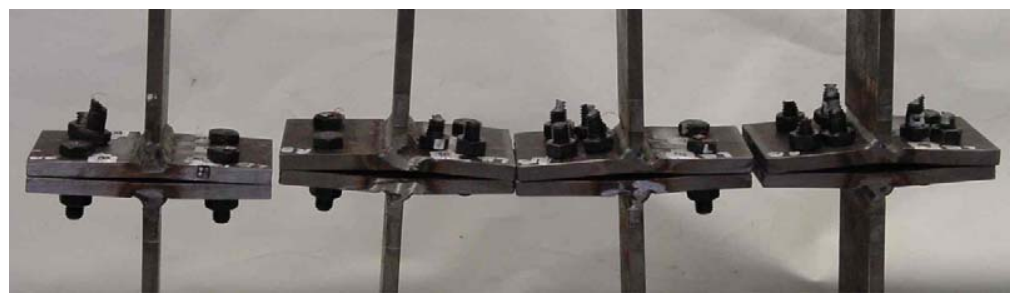

Fig. 29. Comparison of the deformation of specimens WT51, WT53C, WT53D and WT53E (from left to right) at failure. 


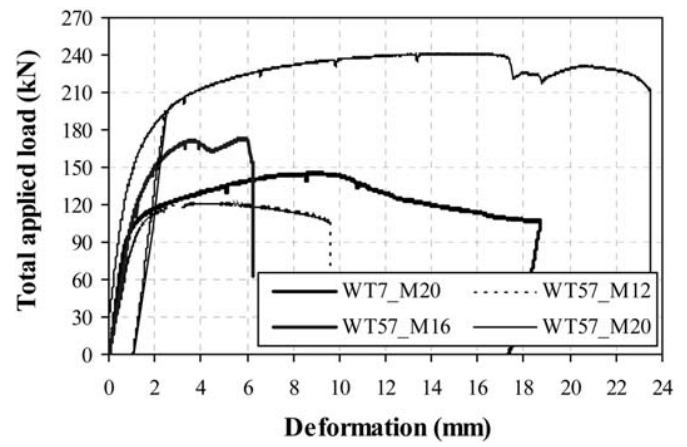

Fig. 30. Experimental load-carrying behaviour of specimen series WT57 and comparison with WT7_M20.

Having analysed the influence of the steel grade on the overall T-stub behaviour (mainly: increase of strength and decrease of ductility for higher strength steel grades), the response obtained for series WT57 can be compared with series WT7. In series WT57, when using bolts M12 and M16, the plastic resistance of the specimens, as determined according to Eurocode 3 [11] - Table 8, corresponds to that of a plastic mechanism type-2 whilst for M20 it corresponds to a type-1 plastic mechanism. This is evident in the graphs from Fig. 30 where the responses of the three specimens are shown. For comparison, WT7_M20 is also included. Worth mentioning is the fact that the bolt was also engaged in collapse in the case of the highstrength steel (WT57_M20) since the specimen failed in a combined failure mode (type AC), whilst in WT7_M20 collapse was governed by plate cracking near the weld toe only. Basically, the conclusions drawn above are corroborated with this series of experiments (summary in Table 9).

\subsection{Experimental results for the stiffened test specimens and the rotated configurations}

\subsubsection{Influence of a transverse stiffener}

If a transverse stiffener is added to a T-stub connection, stiffness and resistance properties improve and deformation capacity decreases. To support this statement, first consider series WT61 that was obtained from the original WT1 by including a transverse stiffener in order to simulate the T-stub model for the end plate side (Fig. 1b). The load-carrying behaviour of the two specimens included in this series is compared with specimen WT1h and the code predictions [11] in Fig. 31 and Tables 8 and 9. The collapse of the specimens was determined by bolt fracture at the stiffener side (Fig. 14c) - labelled "left side". Fig. 32 plots the bolt elongation behaviour against the overall deformation for specimens WT61a and WT1h. Whilst for WT61a the record of the bolt elongation was carried out nearly until collapse, for WT1h, the measuring brackets were removed at an earlier stage and 


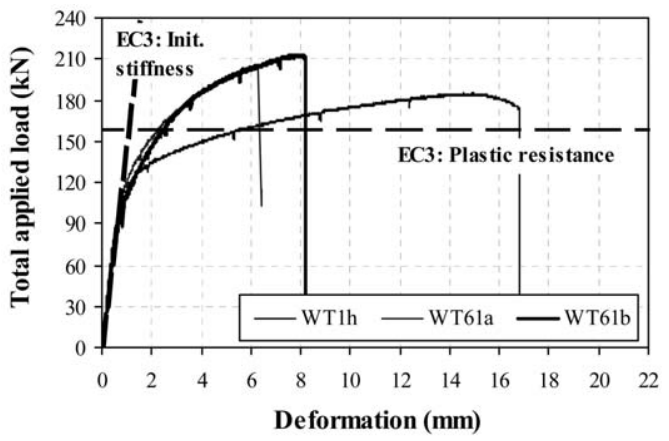

Fig. 31. Experimental load-carrying behaviour of specimen series WT61 and comparison with WT1h and Eurocode 3 predictions.

therefore the loss of stiffness in this response, which is evident for WT61a, is not plotted in the graph. This loss of stiffness does not occur for the unbroken bolt RB (unstiffened side), whose response is very close to the bolts from WT1h.

Now consider the stiffened specimen WT64C that derived from series WT4A by inclusion of the stiffeners. The above conclusions are not so obvious in this case. Fig. 33 and Table 9 show that both initial and post-limit stiffness values are identical for the two series. Yet, resistance is still higher in the stiffened case. With respect to the ductility properties, if the absolute maximum deformation is taken into account, then WT64C shows improved ductility; if the deformation capacity is assumed as the level corresponding to $F_{\max }$ instead, the unstiffened case shows higher deformation capacity, as expected. For specimen WT64C some strain results are given in Fig. 34 (see Fig. 10d for indication of the strain gauges nomenclature) and they prove that the flange was not engaged in collapse, as the strain level is low at failure conditions. Fig. 35 compares the strains at equivalent strain gauges

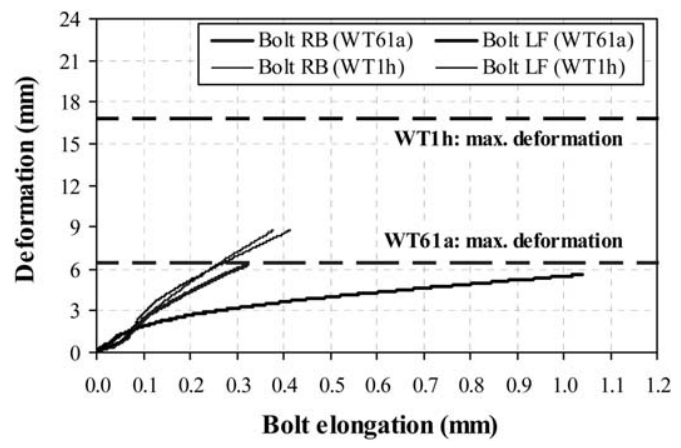

Fig. 32. Comparison of the overall deformation-bolt elongation response for bolts LF and RB in specimens WT1h and WT61a. 


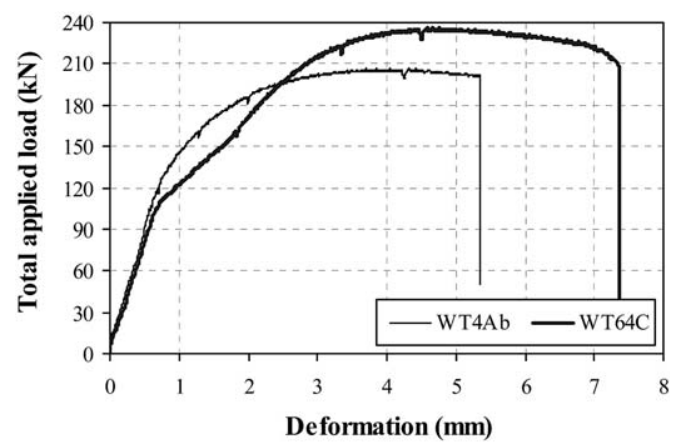

Fig. 33. Experimental load-carrying behaviour of specimen series WT64C and comparison with WT4Ab.

in WT4A and WT64C. At the bolt axis, the strain level is higher in WT64C (Fig. 35a), whilst at the weld toe the strains are higher in WT4Aa (Fig. 35b).

Finally, series WT64A is identical to WT64C but only one of the T-stub elements is stiffened. The results for both specimens are analogous (Fig. 36, Tables 8 and 9). The deformation behaviour is illustrated at two different load stages in Fig. 37.

So, in fact, the main effect of the transverse stiffness is the increase of stiffness and resistance and decrease of ductility of the connection. The two stiffened specimen series also indicate that a trilinear curve best fits the experiments rather than a bilinear approximation as suggested for the other cases.

A final remark concerns the evaluation of $k_{\mathrm{e} .0}$ and $F_{\mathrm{Rd}}$ for these specimens, according to Eurocode 3 [11]. A simplification is introduced: both properties are evaluated for full stiffened and unstiffened specimens and then the average value is taken (Table 8).

\subsubsection{Influence of the $T$-stub orientation}

To assess the influence of the T-stub orientation, consider series WT4B and WT64B. They were identical to specimen WT4A and WT64A, respectively, by rotating $90^{\circ}$ one of the T-stubs. In these tests, the flanges were bent in two directions with double curvature in the plan ( $x$ and $z$ directions)-Figs. 14d and 38 . Contrary to the previous tests, here there was no gap between the flanges, except at the stiffener side in WT64B (Fig. 14d). For WT4B, both flanges were bent as a whole until the bolt started deforming excessively. At this time, at the bolt centrelines, the flanges started opening and the maximum deformation at the web was nearly equal to the bolt deformation capacity. Fig. 39 illustrates the $F-\Delta$ response. It shows results for HP1, HP2 and HP3. HP1 (at the back) shows that the two plates on this side were compressed and their displacement is negative. HP2 and HP3, located at the front and left sides, respectively, show that the plates were compressed until a certain load level is reached, but then they started "opening" and there is an inversion of the deformation. That inversion started at a lower load 


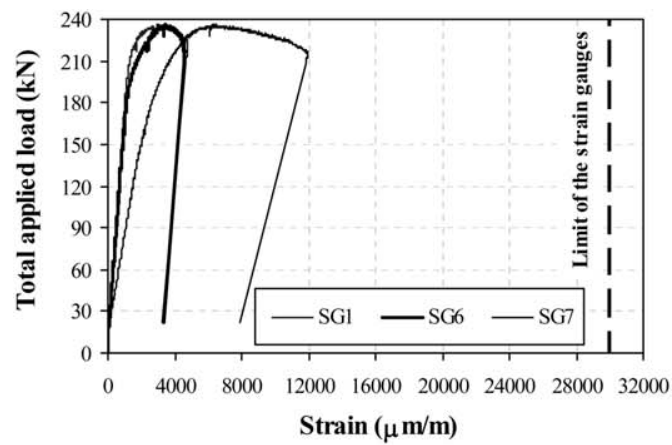

(a) Strain gauges SG1, SG6 and SG7.

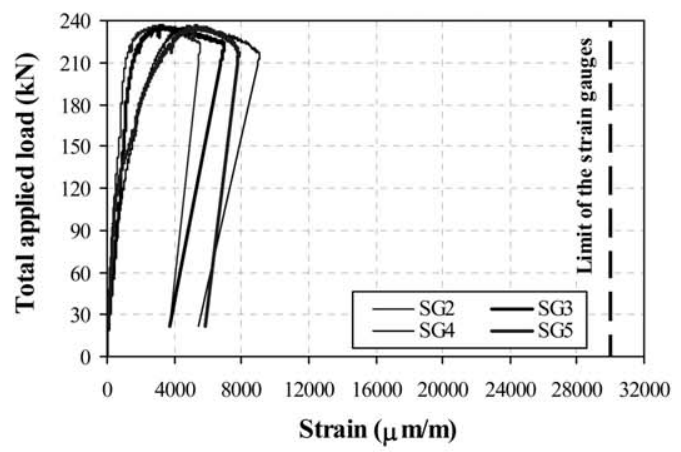

(b) Strain gauges SG2, SG3, SG4 and SG5.

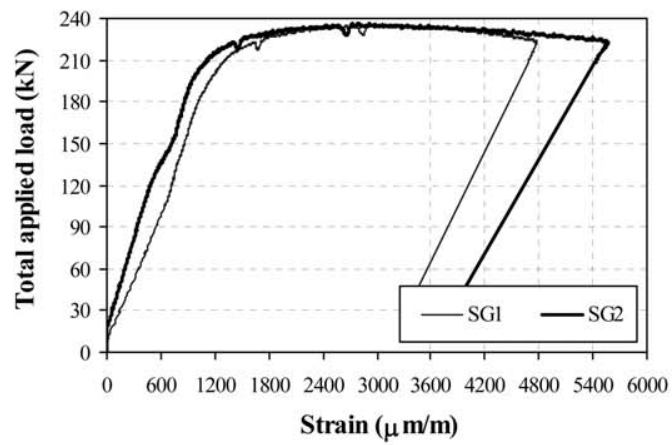

(c) Strain gauges SG1 and SG2.

Fig. 34. Experimental results for the flange behaviour (specimen WT64C). 


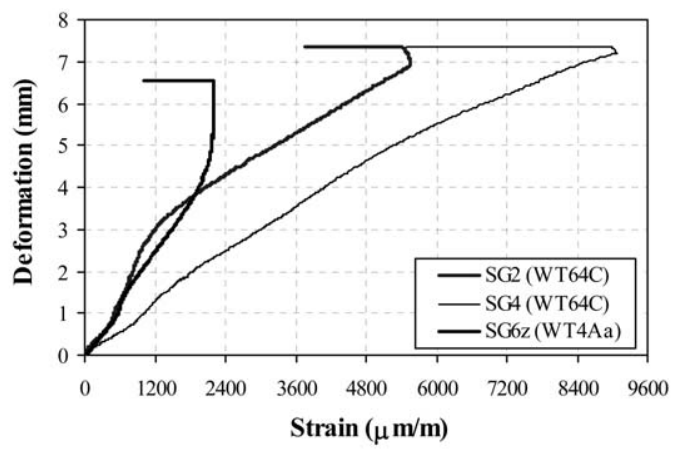

(a) Strain gauges SG2and SG2 from WT64C and SG6z from WT4Aa.

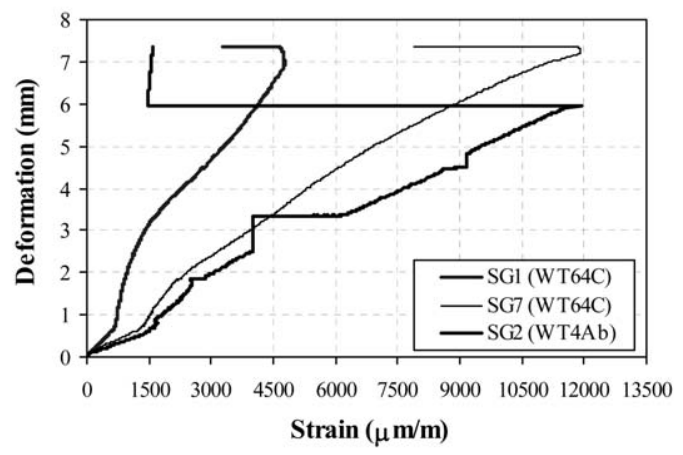

(b) Strain gauges SG1 and SG7 from WT64C and SG2 from WT4Aa.

Fig. 35. Experimental results for the flange behaviour: comparison between specimens WT64C and WT4Ab.

level for HP3 and became positive close to the maximum load. For comparison, Fig. 39 also plots the deformation of WT4B against the average gap of specimen WT4Ab. Clearly, no resemblance between results is observed. The maximum load for specimen WT4B $(223.67 \mathrm{kN})$ was close to the maximum load of WT4Aa, but a bit higher though.

For specimen WT64B similar conclusions are drawn (Fig. 40a and b) except at the stiffener side where the two flange plates "open" from the commencement of loading.

The results for LVDTs HP2 and HP3 for both specimens WT4B and WT64B are compared in Fig. 40c. They are identical apart from the influence of the stiffener. The $F-\Delta$ response, as given by HP2, for WT64Bb and WT64A is compared in Fig. 40d. Similar behaviour is observed. 


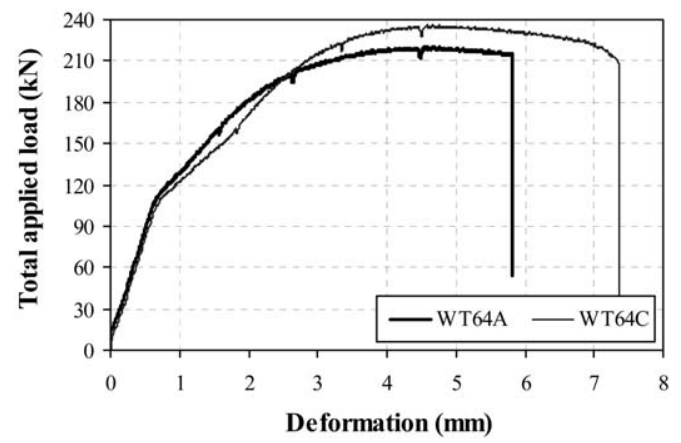

(a) Average gap (LVDTs HP1 and HP2).

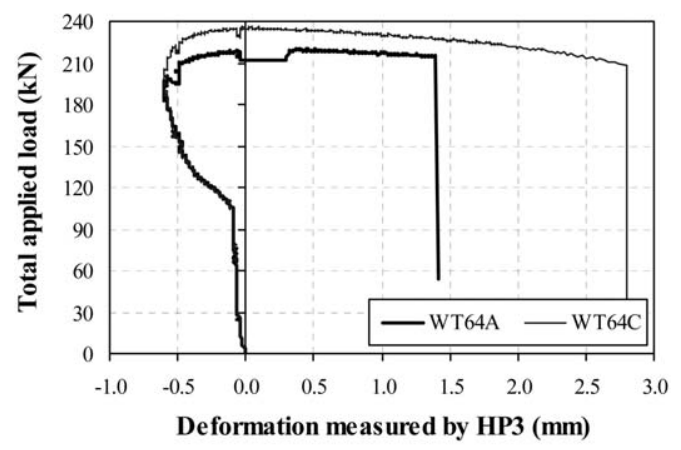

(b) LVDT HP3.

Fig. 36. Experimental load-carrying behaviour of specimen series WT64A and comparison with WT64C.

It should be noted though that some perturbations might have occurred in the measurement by means of the LVDTs in these series since the devices are not so easily attached here.

\section{Concluding remarks}

The experimental results presented above can be regarded as a reliable database for the characterization of the behaviour of the T-stub assembly made up of welded plates. The test procedure and the instrumentation setup adopted for the programme were satisfactory, as evidenced by the identical results obtained from the various sets of tests from one series.

The programme provides insight into the assessment of failure modes and available deformation capacity of bolted T-stub connections. The major contributions of the overall T-stub deformation are the flange deformation and the tension bolt elongation. Usually, a higher deformation capacity of the T-stub is expected if the flange cracking governs the collapse instead of bolt fracture. However, in this type 


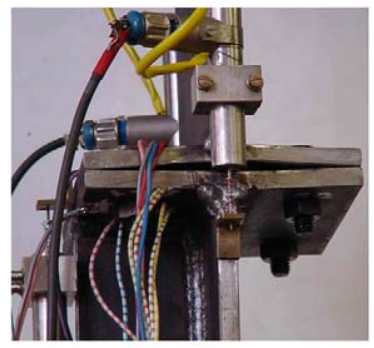

(i) WT64A $(F=214 \mathrm{kN} ; \Delta=4.46 \mathrm{~mm})$.

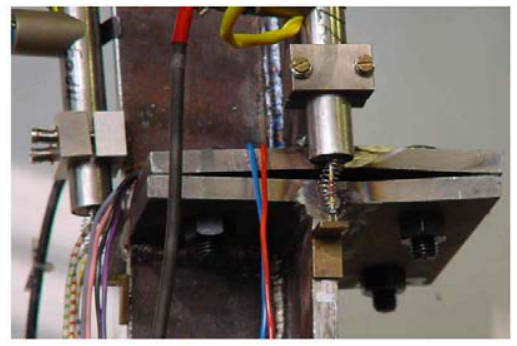

(ii) WT64C $(F=231 \mathrm{kN} ; \Delta=4.49 \mathrm{~mm})$.

(a) After removal of the measuring brackets.

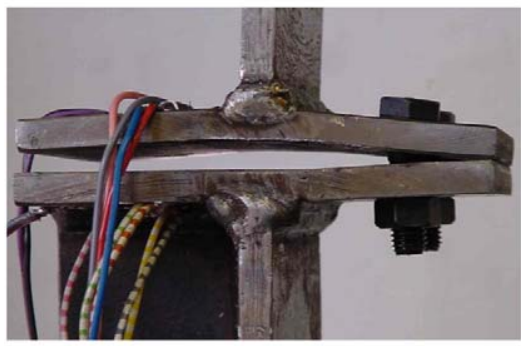

(i) WT64A.

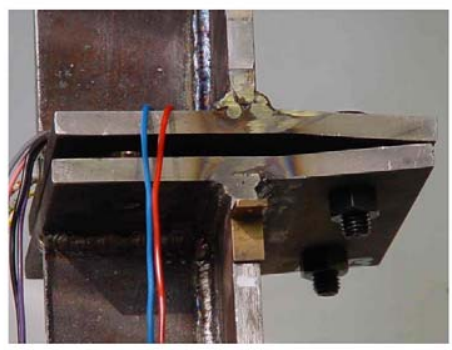

(ii) WT64C.

(b) After failure.

Fig. 37. Deformation of the specimens WT64A and WT64C at two different load stages.

of assembly this statement is not so straightforward. The cracking associated to the flange mechanism, in this case, depends on structural constraint conditions and modifications in the mechanical properties in the HAZ, particularly those linked to the presence of residual stresses. Therefore, the selection of the electrodes and welding procedures is of utmost importance in this connection type to ensure a
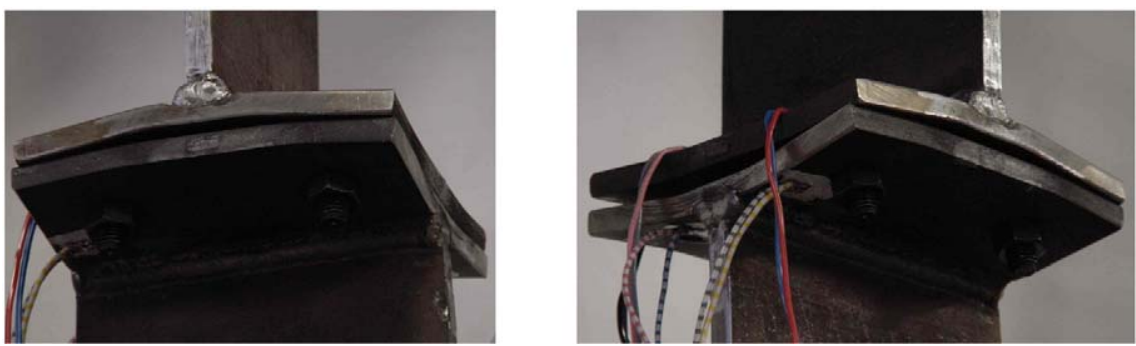

Fig. 38. Deformation of specimen WT4B at failure (two different views). 


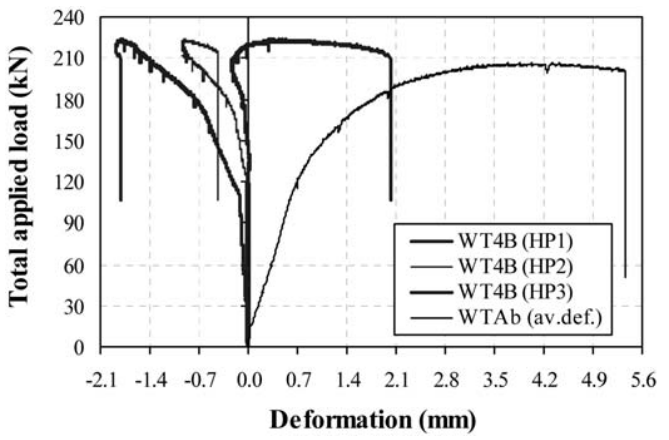

Fig. 39. Experimental load-carrying behaviour of specimen series WT4B and comparison with WT4A.

ductile behaviour. It has been found out that soft, low hydrogen, mismatch (or evenmatch) electrodes prevent an early cracking of the flange thus enhancing the overall deformation capacity.

Regarding the definition of "deformation capacity", some clarification seems appropriate: "which criterion should be considered to define the deformation capacity?". This question was addressed previously by the authors [24] since the designation adopted so far (deformation capacity taken as the deformation level at maximum load) is very conservative (e.g. WT1g, WT53C, WT7_M20, WT64C, among others). In many examples, there is a long plateau in the $F-\Delta$ response after the maximum load level is reached that cannot be disregarded. Then, some guideline on this specific issue is desirable.

Finally, the main conclusions drawn from the experiments concerning the influence of the geometrical and mechanical variables tested are:

- The increase of the weld throat thickness improves stiffness and resistance but decrease the deformation capacity;

- The effect of the width of the T-stub is identical to the above;

- Long-threaded bolts increase the overall deformation capacity of a T-stub connection when compared to short-threaded equivalent bolts, if collapse is governed by bolt fracture;

- Higher bolt diameters increase the strength of the bolt and therefore enhance the three characteristic properties of the load-carrying behaviour of the connection: resistance, stiffness and ductility;

- Identical T-stubs yield higher resistance and lower deformation capacity for higher steel grades;

- The main effect of the stiffener is the decrease of the deformation capacity; it should also be noted that a trilinear approximation for simplified calculations best fits the experimental results rather than the classical bilinear approximation;

- For stiffened T-stubs, the influence of the elements orientation is not relevant at the stiffener side; in the case of unstiffened specimens it was concluded that the two plates become in contact when the connection is subjected to tension. 


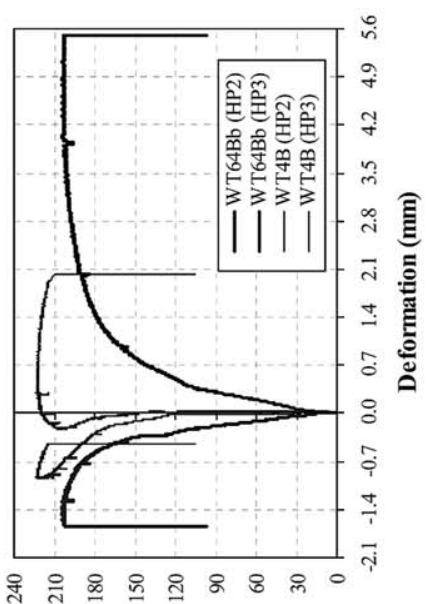

(NY) peoI pọ़dde [ęoL

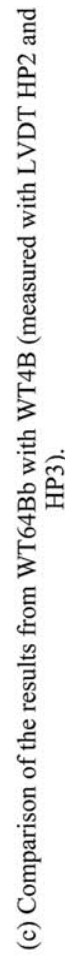

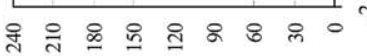

(NY) peoI pə!̣dde [вฺOL

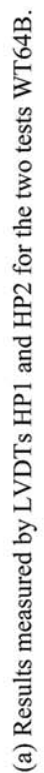

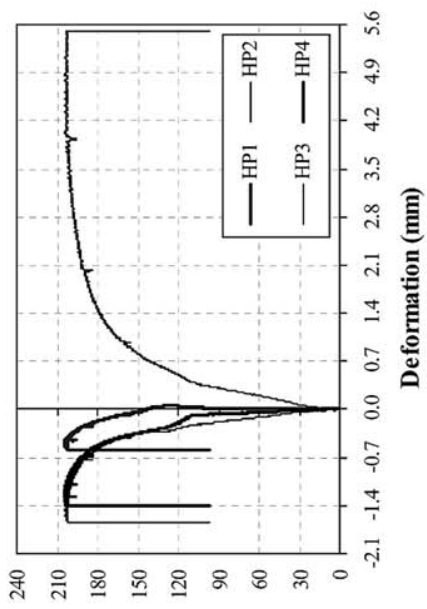

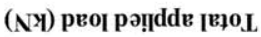




\section{Acknowledgements}

Financial support from "Fundação para a Ciência e Tecnologia (Ministério da Ciência e Ensino Superior)" and "PRODEP - Acção de Formação Avançada de Docentes do Ensino Superior (Ministério da Educação)” for Ana M. Girão Coelho is gratefully acknowledged.

\section{References}

[1] Weynand K, Jaspart JP, Steenhuis M. The stiffness model of revised Annex J of Eurocode 3. In: Bjorhovde R, Colson A, Zandonini R, editors. Connections in Steel Structures III. Proc. of the 3rd Intern. Workshop on Connections, Trento. 1995, p. 441-52.

[2] Zoetemeijer P. A design method for the tension side of statically loaded bolted beam-to-column connections. Heron 1974;20(1):1-59.

[3] Packer JA, Morris LJ. A limit state design method for the tension region of bolted beam-to-column connections. Struct Eng 1977;55(10):446-58.

[4] Yee YL, Melchers RE. Moment-rotation curves for bolted connections. J Struct Eng ASCE 1986;112(3):615-35.

[5] Jaspart JP. Etude de la semi-rigidite des noeuds poutre-colonne et son influence sur la resistance et la stabilite des ossatures en acier. Ph.D. Thesis. University of Liège, Liège; 1991 [in French].

[6] Bursi OS, Jaspart JP. Benchmarks for finite element modelling of bolted steel connections. J Construct Steel Res 1997;43(1):17-42.

[7] Faella C, Piluso V, Rizzano G. Experimental analysis of bolted connections: snug versus preloaded bolts. J Struct Eng ASCE 1998;124(7):765-74.

[8] Gebbeken N, Wanzek T. Benchmark experiments for numerical simulations of T-stubs. In: Virdi KS, editor. Numerical simulation of semi-rigid connections by the finite element method. COST C1, Report of working group 6-Numerical simulation, Brussels; 1999. p. 61-70.

[9] Swanson JA, Leon RT. Bolted steel connections: tests on T-stub components. J Struct Eng ASCE 2000;126(1):50-6.

[10] Piluso V, Faella C, Rizzano G. Ultimate behavior of bolted T-stubs. II: Model validation. J Struct Eng ASCE 2001;127(6):694-704.

[11] European Committee for Standardization (CEN). Eurocode 3. prEN 1993-1-8:20xx, Part 1.8: Design of joints, Eurocode 3: Design of steel structures, Final draft (corrected), February 2002, Brussels; 2002.

[12] Simões da Silva L, Santiago A, Vila Real P. Post-limit stiffness and ductility of end-plate beam-tocolumn steel joints. Comput Struct 2002;80:515-31.

[13] Swanson JA, Leon RT. Stiffness of bolted T-stub connection components. J Struct Eng ASCE 2001;127(5):498-505.

[14] Piluso V, Faella C, Rizzano G. Ultimate behavior of bolted T-stubs. I: Theoretical model. J Struct Eng ASCE 2001;127(6):686-93.

[15] Girão Coelho AM, Simões da Silva L. Numerical evaluation of the ductility of a bolted T-stub connection. In: Chan SL, Teng JG, Chung KF, editors. Advances in steel structures. Proc. of 3rd International Conference (ICASS'02), Hong Kong. 2002, p. 277-84.

[16] Girão Coelho AM, Bijlaard F, Simões da Silva L. On the deformation capacity of beam-to-column bolted connections. European Convention for Constructional Steelwork-Technical Committee 10, Structural Connections (ECCS-TC10), Document ECCS-TWG 10.2-02-003; 2002.

[17] Girão Coelho AM, Bijlaard F, Simões da Silva L. On the behaviour of bolted end plate connections modelled by welded T-stubs. In: Lamas A, Simões da Silva L, editors. Steel strucutres. Proc. of the 3rd European Conference (Eurosteel), Coimbra. 2002, p. 907-18.

[18] European Committee for Standardization (CEN). prEN 10025:2000E: Hot rolled products of structural steels, September 2000, Brussels; 2000. 
[19] European Committee for Standardization (CEN). EN 10204:1995E: Metallic products, October 1995, Brussels; 1995.

[20] RILEM draft recommendation. Tension testing of metallic structural materials for determining stress-strain relations under monotonic and uniaxial tensile loading. Mater Struct 1990;23:35-46.

[21] Gioncu V, Mazzolani FM. Ductility of seismic resistant steel structures. London: Spon Press; 2002.

[22] Rodrigues DM, Menezes LF, Loureiro A, Fernandes JV. Numerical study of the plastic behaviour in tension of welds in high strength steels. Int J Plasticity 2004;20:1-18.

[23] Davies AC. The science and practice of welding-welding science and technology, Vol. I. Cambridge: Cambridge University Press; 1992.

[24] Girão Coelho AM, Bijlaard F, Simões da Silva L. On the deformation capacity of beam-to-column bolted connections. European Convention for Constructional Steelwork-Technical Committee 10, Structural Connections (ECCS-TC10), Document ECCS-TWG 10.2-217; 2002.

[25] European Committee for Standardization (CEN). EN 499:1994E: Welding consumables-Covered electrodes for manual metal arc welding of non alloy and fine grain steels-Classification, December 1994, Brussels; 1994. 